\title{
RECENT DEVELOPMENT IN ULTRAVIOLET SPECTROPHOTOMETRY THROUGH THE LAST DECADE (2006-2016): A REVIEW
}

\author{
HAYAM M. LOTFYa,b, SARAH S. SALEH ${ }^{*}$ \\ aAnalytical Chemistry Department, Faculty of Pharmacy, Cairo University, Kasr-El Aini, 11562 Cairo, Egypt, bPharmaceutical Chemistry \\ Department, Faculty of Pharmaceutical Sciences and Pharmaceutical Industries, Future University in Egypt (FUE), 12311 Cairo, Egypt, \\ 'Analytical Chemistry Department, Faculty of Pharmacy, October University for Modern Sciences and Arts (MSA), 11787 6 $^{\text {th }}$ October, Egypt \\ Email: drsarahsalah@gmail.com
}

Received: 17 Jun 2016 Revised and Accepted: 12 Aug 2016

\begin{abstract}
Several techniques have been proposed for treatment of spectrophotometric data, with the objective of extracting the largest amount of analytical information from spectra composed of unresolved bands. The instrumental development and analytical applications of UV regions absorption spectrophotometry produced in the last $10 \mathrm{y}$ (since 2006) are reviewed. The methods were classified according to the spectra data used, including zero order absorption, derivative and ratio amplitudes. The proposed methods were applied to solve different complex pharmaceutical mixtures and the obtained results were accepted when compared to other reported methods.
\end{abstract}

Keywords: Spectral Manipulation, Ratio spectra, Amplitude, Differential, Successive, Absorptivity

(c) 2016 The Authors. Published by Innovare Academic Sciences Pvt Ltd. This is an open access article under the CC BY license (http://creativecommons. org/licenses/by/4. 0/) DOI: http://dx.doi.org/10.22159/ijpps.2016v8i10.13537

\section{INTRODUCTION}

Analytical studies, related to the quality control and routine analysis of commercial products in the research or industry laboratories, use spectrophotometric methods such as derivative spectrophotometry, ratio spectra spectrophotometry. These spectrophotometric methods are found to be preferable instead of hyphenated analytical instrumentations or techniques such as LC-MS, GC-MS, LC-NMR, etc; which always require prior steps such as extraction and other tedious analytical process during analysis. On the other hand, the related techniques having complex components bring high cost and time consumption.

Taking into account all above arguments, the quantitative spectrophotometric resolution of the mixtures of two or more compounds having overlapped spectra is an interesting issue for analytical chemists. Besides, the existing spectrophotometric methods were found to be very simple to apply, very rapid, sensitive and yet very cost-affordable for analysis of any mixture. For resolving complex mixtures, the analytical chemist needs new analytical methods or approaches to obtain accurate, precise and reliable results. Therefore, the analytical chemists have focused mainly on the use of a new mathematical technique or the combined use of the mentioned approaches together with traditional analytical techniques.

The diversity of the spectrophotometric methods is considered the most important feature of spectrophotometric analysis, where it gives the analyst a chance to choose the most suitable method for analysis.

Absorption spectroscopy is one of the most powerful and widely used tools for the quantitative analysis of any analyte. The relation between the concentration of the analyte and the amount of light absorbed is the basis of most analytical applications of molecular spectroscopy. This method of analysis is gaining importance due to simple, rapid, precise, highly accurate and less time consumption Spectrophotometric multi-component analysis can be applied where the spectra of drugs overlaps. In such cases of overlapping spectra, the simultaneous equation can be framed to obtain the concentration of each individual component; otherwise, multicomponent analysis can be applied on any degree of spectral overlap provided that two or more spectra are not similar exactly.
The basis of all the spectrophotometric techniques for multicomponent samples is the following properties which apply through all wavelengths:

a) The absorbance of a solution is the sum of absorbance of its individual components; the absorption of light by the components of the sample solution is additive; that is, the total absorption of light at any given wavelength is equal to the sum of the absorbance which the two substances would show if measured individually under the same conditions. This was confirmed experimentally by demonstrating that the spectrum of the analyte mixture is the sum of the spectra of the two components measured separately because the absorbance are additive; and thus if the spectrum of one component is subtracted from total solution absorbance, the spectrum of the second component is obtained [1]

b) The measured absorbance is the difference between the total absorbance of the solution in the sample cell and that of the solution in the reference (blank) cell [2, 3]

c) The Beer-Lambert Law $(A=a b c)$ implies that when concentration is equal to zero ( $c=0)$, absorbance must also be zero $(\mathrm{A}=0)$ at path length $=1$. In other words, the calibration line must pass through the origin. You will find in your experiment that the calibration plot generally does not pass exactly through the origin, but it should be quite close. Thus, the value you see for the intercept (b) in the equation $y=m x+b$ will be small. A major source of error in the spectrophotometric analysis is applying the Beer-Lambert Law at inappropriate concentrations. The Beer-Lambert Law is strictly applicable only for dilute solutions. It becomes less and less accurate as the concentration of the solution increases. Once you have the calibration curve set up, you can measure the absorbance of any unknown solution at the same wavelength and read off its concentration from the graph or calculate from the slope [4] .

For single component analysis, spectrophotometric determination of colored complex products or adjuvants can be applied [5-7] . But these methods are not suitable for the analysis of multi-component mixtures. So, According to the extent of overlapping, the methods were classified to either solving partially or severely overlapped spectra. The various spectroscopic techniques used for multicomponent analysis are classified basing on manipulation steps on different spectra. 
Methods applied on zero order absorption spectra

\section{Methods based on dual-wavelength}

\section{Induced dual wavelength method (IDW)}

This novel method [8] can be applied for a binary mixture of X and $Y$ with severely overlapped zero order absorption spectra at two wavelengths $\lambda_{1}$ and $\lambda_{2}$, where the absorbance of the interfering substance at those two wavelengths aren't equal (absorbance difference does not equal zero), so the conventional dualwavelength method $[9,10]$ cannot be applied. To cancel the effect of $\mathrm{Y}$ at the two selected wavelengths, the equality factor of pure $\mathrm{Y}$ at these wavelengths $\left(\mathrm{F}_{\mathrm{Y}}\right)$ is calculated and consequently the absorbance difference between two selected wavelengths of the mixture spectra is directly proportional to the concentration of component $\mathrm{X}$

The concentration of $\mathrm{X}$ is calculated using the regression equation (obtained by plotting the absorbance difference values of the zero order spectra of $X$ at the two chosen wavelengths $\left(\Delta A=A_{1}-F_{Y} A_{2}\right)$ against their corresponding concentrations $X$. The concentration of $Y$ is calculated using the same procedure which can be done to calculate the concentration of $\mathrm{Y}$ using the equality factor of pure $\mathrm{X}$ at the two chosen wavelengths $\left(\mathrm{F}_{\mathrm{X}}\right)$.

\section{Dual wavelength resolution technique (DWRT)}

This novel resolution technique [8] can be applied for a binary mixture of $\mathrm{X}$ and $\mathrm{Y}$ with complete overlapped zero order absorption spectra, where the absorbance difference $\Delta \mathrm{A}\left(\mathrm{A}_{1}-\mathrm{F}_{\mathrm{Y}} \mathrm{A}_{2}\right)$ between two selected wavelengths $\left(\lambda_{\max }\right.$ of $X$ and $\left.\lambda_{2}\right)$ on the mixture spectra is directly proportional to the concentration of component $X$; while for component $Y$ the absorbance difference inherently equals to zero. Dual wavelength resolution technique (DWRT) is a technique used for solving the overlapping spectra via dual wavelength spectrophotometric methods (conventional dual wavelength method $[9,10]$ or induced dual wavelength [8] ), where those methods are used for the determination of the first component $(\mathrm{X})$; meanwhile they are not applicable for the second component $(\mathrm{Y})$. This could be done by measuring $(X)$ using either the conventional dual-wavelength (where $F_{Y}=1$ ) or using the equality factor as in induced dual wavelength (where $\mathrm{F}_{\mathrm{Y}} \neq 1$ ).

A calibration curve is constructed for pure $\mathrm{X}$ representing the relationship between the concentration of $X$ and absorbance difference $\Delta \mathrm{A}\left(\mathrm{A}_{\max }-\mathrm{F}_{\mathrm{Y}} \mathrm{A}_{2}\right)$, where the concentration of $\mathrm{X}\left(\mathrm{C}_{\mathrm{x}}\right)$ can be calculated using the corresponding regression equation.

Zero order absorption spectrum of component $\mathrm{X}$ in the mixture is then obtained by multiplying the calculated concentration of $\mathrm{X}$ by the normalized spectrum of $X$, which is obtained by dividing the whole spectrum of $\mathrm{X}$ by its corresponding concentration to obtain a new spectrum represents the absorptivity of the analyte of interest (ax) versus all the measured wavelengths.

Zero order absorption spectrum of a component of $Y$ can be then obtained by spectrum subtraction by subtracting the obtained spectrum of $X$ from the spectrum of the mixture $(X+Y)$ as, therefore we can obtain the $\mathrm{D}{ }^{\circ}$ spectrum of $\mathrm{Y}$. The concentration of component $\mathrm{Y}$ in the mixture is calculated using the regression equation (obtained by plotting the absorbance values of the zero order curves of $Y$ at its $\lambda_{\max }$ against its corresponding concentration).

\section{Absorption correction method (ACM)}

This method [11, 12] describes the analysis of a binary mixture where the two components $X$ and $Y$ have overlapped spectra. $Y$ shows interference at $\lambda_{\max }$ of $X\left(\lambda_{1}\right)$, while $X$ shows no interference with $Y$ at another wavelength $\left(\lambda_{2}\right)$. The average value of absorption factor of component $Y$ (Abs at $\lambda_{1 / A b s}$ at $\lambda_{2}$ ) is calculated. Since the absorbance of the mixture $(\mathrm{X}+\mathrm{Y})$ at $\lambda_{2}$ equal to that of pure $\mathrm{Y}$ due to lack of contribution of $X$ at this wavelength, so the absorption of $X$ at $\lambda_{1}$ could be calculated using the following equation:

$$
\text { Abs of } \mathrm{X} \text { at } \lambda_{1}=\mathrm{Abs} \lambda_{1}(\mathrm{X}+\mathrm{Y})^{-\frac{a b s 1}{a b s 2}} \times \operatorname{Abs} \lambda_{2}(\mathrm{X}+\mathrm{Y})
$$

Where; $\frac{a b s 1}{a b s 2}$ is absorption factor of pure Y (Abs at $\lambda_{1}$ Abs at $\lambda_{2}$ ), Abs $\lambda_{1}$ and Abs $\lambda_{2}$ are the absorbance of the mixture of $(X+Y)$ at $\lambda_{1}$ and $\lambda_{2}$, respectively. The concentrations of $\mathrm{X}$ and $\mathrm{Y}$ will be calculated from the corresponding regression equation obtained by plotting the absorption values of the zero order spectra, at $\lambda_{1}$ and $\lambda_{2}$, against their concentrations, respectively.

\section{Methods based on absorptivity points}

\section{Absorbance subtraction (AS)}

This novel method $[13,14]$ is based on isoabsorption point spectrophotometric method. The word derives from two Greek words: (isos): equal and (absorptive): absorptivity; means the same absorptivity. It was used for simultaneous determination of components in binary or ternary mixtures $[15,16]$.

At the isoabsorption point, the mixture of drugs acts as a single component as they exhibit equal absorptivity value. Thus, by measuring the absorbance value at the chosen isoabsorption point $\left(\lambda_{\text {iso }}\right)$, the total concentration of both $(\mathrm{X})$ and $(\mathrm{Y})$ could be calculated using absorbance at $\left(\lambda_{\text {iso }}\right)$, while the concentration of one of the components in the mixture could be determined using any complementary method.

The AS method is based on the same principles as the absorbance correction method [12] . It could be applied for the analysis of a mixture of two drugs $\mathrm{X}$ and $\mathrm{Y}$ having overlapped spectra intersecting at isoabsorption point where $\mathrm{Y}$ is extended over $\mathrm{X}$, and $\mathrm{X}$ doesn't show any contribution at another wavelength $\left(\lambda_{2}\right)$.

In this method the isoabsorption point $\lambda_{\text {iso }}$ could be used for separate quantitative estimation of each $\mathrm{X}$ and $\mathrm{Y}$ in their mixture $(X+Y)$. The determination can be done using mathematically calculated the factor of one of these components. By simple manipulation step, we can obtain the absorbance value corresponding to X and Y, separately. So, the concentration of each component could be obtained via the isoabsorption point regression equation without any need for a complementary method.

The concentration of each $\mathrm{X}$ and $\mathrm{Y}$, separately, is calculated using the isoabsorption point unified regression equation (obtained by plotting the absorbance values of the zero order curves of either $X$ or $\mathrm{Y}$ at $\lambda_{\text {iso }}$ against their corresponding concentrations of $\mathrm{X}$ or $\mathrm{Y}$ respectively).

\section{Advanced absorbance subtraction}

This novel method [17] can be applied for a binary mixture of $\mathrm{X}$ and $Y$, where their spectra is completely overlapped and show isoabsorption point $\left(\lambda_{\text {iso }}\right)$ at the zero spectrum. Two wavelengths are selected $\left(\lambda_{\text {iso }}\right.$ of $X$ and $\left.\lambda_{2}\right)$ where component $Y$ shows equal absorbance at these wavelengths. The absorbance difference $\Delta \mathrm{A}$ $\left(\mathrm{A}_{\text {iso }}-\mathrm{A}_{2}\right)$ between two selected wavelengths on the mixture spectra is directly proportional to the concentration of component $\mathrm{X}$; while for component $Y$ the absorbance difference inherently equals to zero. A calibration curve is constructed for pure $\mathrm{X}$ representing the relationship between $\left(\mathrm{A}_{\text {iso }}-\mathrm{A}_{2}\right)$ and $\mathrm{A}_{\text {iso }}$ and the following regression equation is formulated:

$$
\left(A_{i s o}-A_{2}\right)=b_{\triangle A} A_{i s o}+I_{\triangle A}
$$

Where $\left(A_{\text {iso }}-A_{2}\right)$ is the absorbance difference between two selected wavelengths for pure $\mathrm{X}$ spectra, $A_{\text {iso }}$ absorbance at $\lambda_{\text {iso }}$ of $X, b_{\Delta A}$ is slope and $I_{\triangle A}$ is intercept.

Substituting the absorbance difference $\Delta A\left(A_{\text {iso- }} A_{2}\right)$ between the two selected wavelengths of the mixture spectrum in the previous equation, the absorbance $A_{\text {postulated }}$ corresponding to the absorbance of $\mathrm{X}$ only at $\mathrm{A}_{\text {iso }}$ is obtained.

By subtracting the postulated absorbance of $X$ at $A_{\text {iso }}$ from the practically recorded absorbance [A Recorded $]$ at $A_{\text {iso }}$ to get that corresponding to $\mathrm{Y}$

$$
A_{\text {Recorded }}=A_{X}+A_{Y}
$$


Then the concentration of $\mathrm{X}\left(\mathrm{C}_{\mathrm{x}}\right)$ or $\mathrm{Y}\left(\mathrm{C}_{\mathrm{Y}}\right)$ can be calculated using the unified regression equation obtained by plotting its zero order absorbance values $\left(\mathrm{A}_{\text {iso }}\right)$ against the corresponding concentration of $\mathrm{X}$ or $\mathrm{Y}$.

\section{Absorptivity factor spectrophotometric method (a-Factor method)}

This novel absorptivity factor spectrophotometric method [18] for the analysis of binary mixtures. It depends on applying a simple mathematic equation to calculate the concentration of both components in a binary mixture where there is a large difference in the absorptivity between both components in a mixture so that no isoabsorption point occurs. In this case, simultaneous determination of each drug in the presence of the other can't be carried out by applying any of the isoabsorption point techniques. This method depends on the calculation of the absorptivity factor which is the ratio between the two absorptivities ( $\mathrm{ax}$, ay) at the intersection point with the same absorbance value. This point called the absorptivity factor point $\left(\lambda_{\mathrm{F}}\right)$.

So, the concentration of the mixture represent $\left(\mathrm{FC}_{\mathrm{x}}+\mathrm{C}_{\mathrm{Y}}\right)$ can be calculated by using a regression equation representing the linear relationship between the absorbance of $\mathrm{Y}$ and its corresponding concentration at the absorptivity factor point. Thus, if the concentration of $\mathrm{Y}$ can be determined separately by any other method such as direct spectrophotometry, derivative or derivative ratio, then the concentration of $\mathrm{X}$ can be determined after subtraction of concentration $\mathrm{Y}$ and multiplication by the inverse of $\mathrm{F}$ or vice versa.

\section{Methods based on area under the curve (AUC)}

\section{Area under the curve correction method (AUC-CM)}

This novel approach [19] of the area under the curve (AUC) method is a well-established spectrophotometric method $[20,21]$ which provides a simple way to determine the concentration of the component of interest depending on the area of its absorption spectrum.

For a binary mixture where the two components $\mathrm{X}$ and $\mathrm{Y}$ have partially overlapped spectra. At the region of $\left(\lambda_{1}-\lambda_{2}\right)$, while $X$ shows no interference with $\mathrm{Y}$ at another region $\left(\lambda_{3}-\lambda_{4}\right)$; $\mathrm{Y}$ can be determined directly though the AUC in $\left(\lambda_{3}-\lambda_{4}\right)$ due to lack of contribution of $X$ at this region, while the AUC of $X$ at $\left(\lambda_{1}-\lambda_{2}\right)$ can be calculated using area under curve (AUC) factor as follow:

$$
\begin{aligned}
& \operatorname{AUC} \text { of } X \text { at }\left(\lambda_{1}-\lambda_{2}\right)=\operatorname{AUC} \text { at }\left(\lambda_{1}-\lambda_{2}\right) \text { of } X+Y_{-} \frac{\operatorname{AUC}_{(1-2)}}{\operatorname{AUC(3-4)}} \times \operatorname{AUC} \text { at }\left(\lambda_{3}-\lambda_{4}\right) \text { of } \\
& X+Y
\end{aligned}
$$

$A U C_{(1-2)}$

Where; $\overline{A U C_{(3-4)}}$ is AUC factor of pure Y [AUC at $\left(\lambda_{1}-\lambda_{2}\right) /$ AUC at $\left(\lambda_{3}\right.$. $\left.\left.\lambda_{4}\right)\right]$, AUC at $\left(\lambda_{3}-\lambda_{4}\right)$ of $X+Y=A U C$ at $\left(\lambda_{3}-\lambda_{4}\right)$ of $Y$ only.

The main advantage of this method is solving mixture with severely overlapped spectra so by using the area under curve factor we could obtain the corrected area under the curve which represents the concentration of a component of interest. The values of AUC is relatively higher than absorbance value for the same component, even in lower concentrations, which increases sensitivity. This modification can determine the AUC of each of $\mathrm{X}$ and $\mathrm{Y}$ components, where $\mathrm{Y}$ is extended over $\mathrm{X}$, with no need for Cramer's rule.

\section{Compensated area under the curve method (CAUC)}

This method [22] was recently introduced as a modification of the derivative compensation ratio technique $[23,24]$ but instead of using the amplitude of derivative spectra, the area under the curve was used. It could be applied when the absorption spectra of two components $(\mathrm{X})$ and $(\mathrm{Y})$ overlap to a large extent or when analysis of a minor component $(\mathrm{X})$ in the presence of a major component $(\mathrm{Y})$ represents a problem.

This method involves calculating the AUC ratios (range $\mathrm{AUC}_{\mathrm{a}}$ range $\mathrm{AUC}_{\mathrm{b}}$ ) are for pure major component $(\mathrm{Y})$ against a blank solution. The mixture solution containing $(\mathrm{X}+\mathrm{Y})$ is placed in the sample cell and the area under the curve (AUC) was recorded for the difference absorption spectra of [mixture $(\mathrm{m})$-reference $(\mathrm{r})$ ] where $(\mathrm{m}=$ $\left.A_{x}+A_{y}\right)$ and $\left(r=A_{x}\right)$ using different concentration of pure drug $(x)$ above and below that expected in the mixture solution placed in the reference cell $C_{x}$. The AUC ratios of the difference spectra are calculated (AUC a/AUC b) and then compared to the previously obtained AUC ratio of pure (Y). The AUC ratios of the mixture will coincide with AUC of pure $(Y)$ at the balance point, for which $C_{x}$ in the mixture equal to $C_{x}$ in the reference cell.

By applying the geometrical approach, the above-mentioned AUC ratios of the mixture are plotted against the concentration of the minor component $(\mathrm{Cx})$ in the reference cell where a line with very slight curvature is obtained. The concentration $(\mathrm{Cx})$ is calculated from the graph as it is the concentration corresponding to the AUC ratio of the mixture which is equal to the AUC ratio of the pure component $(\mathrm{Y})$ previously obtained from spectra of pure $(\mathrm{Y})$ at different concentration. The regression equation representing the geometrical approach was computed. Then the concentration $(\mathrm{Cx})$ could be determined after substitution in it using the average of AUC ratio of pure $(\mathrm{Y})$.

\section{Spectrum subtraction}

This novel method [25] depends on the property of absorption spectroscopy that the absorption of light by the components of the sample solution is additive; that is, the total absorption of light at any given wavelength is equal to the sum of the absorbance which the two substances would show if measured individually under the same conditions.

This method can be used as complementary method where the zero order $\mathrm{D}_{0}$ spectrum of the first component $(\mathrm{X})$ is obtained firstly by ratio subtraction or constant center methods; and then the second component $(\mathrm{Y})$ could be obtained by using the novel method (spectrum subtraction) by subtracting the obtained spectrum of $X$ from the spectrum of the mixture $(X+Y)$, therefore we can obtain the $D_{0}$ spectrum of $Y$ again. The concentration of $Y$ is calculated from the corresponding regression equation obtained by plotting the absorbance values of the zero order absorption spectra of $Y$ at its $\lambda_{\max }$ against the corresponding concentrations.

The reported applications of the previous novel methods based on zero order absorption spectra are listed in table 1.

\section{Methods applied on derivative spectra}

Derivative spectrophotometry is a well-established technique capable of enhancing the resolution of overlapped spectra. It can be applied for the determination of a substance in the presence of the other, by selecting a wavelength where the contribution of one compound is zero, while the other to be determined has a reasonable value. Derivative spectrophotometry has been applied for the determination of several drugs and elements mixtures and has been applied for the determination of certain drugs in the presence of their degradation products [26-29] .

Recently the direct measurements the drug of interest by conventional derivative technique on zero order absorption spectra (first, second, third and fourth order) or on the ratio spectra falls to get satisfactory results upon analysis of some drugs in their combination so there is a need to develop some methods based on the mathematic manipulation of the derivatized spectra in the lowest order of derivatization with minimum noise effect.

Derivative spectrophotometry keeps all laws of classical spectrophotometry, e. g. dependence of derivative value on analyte concentration and additivity law. These methods summarized as follow:

\section{Amplitude subtraction (AS)}

This method [30] is a modification applied on the two regression equation method to be in the simpler form with minimum manipulating steps. Record the peak amplitude of the mixture at $\lambda_{2}$ and calculate the postulated value at the same wavelength by substitution in the previous equation. The peak amplitude of drug (X) was obtained after subtraction the recorded peak amplitude of the mixture at $\lambda_{1}$ from the postulated value at the same wavelength. 


\section{Modified amplitude subtraction (MAS)}

This novel method [30] is applied for a mixture of two drugs (X) and $(\mathrm{Y})$ where the specific peak of derivative spectra of drug $(\mathrm{X})$ is overlapped with that of drug (Y) at the same wavelengths, so we chose one of these wavelengths $\left(e . g \lambda_{1}\right)$. The concentration of $\mathrm{X}$ was previously calculated by one conventional spectrophotometric method. This calculated concentration of X could be substituted in its computed regression equation to get the peak amplitude of $X$ at $\lambda_{1}$, which is then subtracted from the recorded peak amplitude of mixture at $\lambda_{1}$ to get that corresponding to $\mathrm{Y}$.

\section{Amplitude Factor (P-Factor)}

This novel method [30] based on absorption factor method [12] . This method depends on that if you have a mixture of two drugs $X$ and $Y$ having overlapped derivative spectra. $Y$ has some interference at an amplitude of derivative peak (P) of X $\left(\lambda_{1}\right)$, while $X$ doesn't show any contribution at another wavelength $\left(\lambda_{2}\right)$. Quantitative estimation of $\mathrm{X}$ in the mixture $(\mathrm{X}+\mathrm{Y})$ was carried out by subtracting the amplitude due to $\mathrm{Y}$ at the peak amplitude of $\mathrm{X}$ using experimentally calculated amplitude factor.

\section{Amplitude summation method (A-Sum)}

This novel method [14] is applied for a mixture of $X$ and $Y$, where $X$ and $Y$ spectra show isoabsorption point at the zero spectrum; while first derivative spectra (D) $Y$ shows no contribution of $X$ at a certain wavelength. By calculating the first derivative spectra (D) of equal concentration of $X$ and $Y$, at equal path length. It was found that the D spectra intersect at an isosbestic point at a wavelength which shows shift from the isoabsorption point in zero order spectra.

Since $\mathrm{X}$ and $\mathrm{Y}$ interfere at $\lambda_{\text {iso }}$ and $\mathrm{X}$ doesn't show any contribution at another wavelength $\lambda_{2}$, so the postulated amplitude of $Y$ in the mixture at $\lambda_{\text {iso }}$ can be calculated using response factor between the two proposed wavelengths. The amplitude corresponding to $\mathrm{X}$ could be calculated by the difference between recorded amplitude corresponding to total $(\mathrm{X}+\mathrm{Y})$ and the postulated amplitude corresponding to $\mathrm{Y}$.

\section{Simultaneous derivative ratio spectrophotometry ( $\left.\mathrm{S}^{1} \mathrm{DD}\right)$}

This method [31] was modulated to be simultaneous by coupling with amplitude modulation theory. Before the derivatization step took place, the total concentration was firstly determined at the isoabsorption point of the ratio spectrum using the normalized spectrum as a divisor. Then derivative of these ratio spectra was obtained to remove the constant generated in the division spectrum. Moreover, optimization of the proposed method was simpler than the traditional ${ }^{1} \mathrm{DD}$ method, in which the influence of the divisor concentration was eliminated.

\section{Derivative compensation ratio via regression equation}

This is a new modification [24] of derivative compensation ratio $[23,32]$, the regression equation represent the graphical method was computed, the concentration of $(\mathrm{X})$ could be determined after substitution in it using the average of standard amplitude ratio.

In derivative compensation, ratio method is used when the absorption curves of the 2 components $(\mathrm{X})$ and $(\mathrm{Y})$ overlap to a large extent or when analysis of a minor component in the presence of a major component represents a problem, the balance point or the graphical method can be adopted. Under these conditions, the absorption spectrum of a mixture of two drugs $(\mathrm{X})$ and $(\mathrm{Y})$ assumed to possess gross curve which has no characteristics of either of the pure compounds.

The graphical method enhances the drawback of balance points such as tedious procedure and several uses of a standard solution of the pure sample but still has an error in measuring the concentration of the drug of interest from the graph which was eliminated by this new modification via computation of a regression equation.

The method consists of plotting the above-mentioned $\mathrm{D}^{1}$ amplitude ratios of the mixture against the concentration of the drug $(x)$ in the reference cell where a line with very slight curvature is obtained. The concentration of the drug $(\mathrm{x})$ is calculated from the graph as it is the concentration corresponding to the amplitude ratio of the mixture which is equal to the standard amplitude ratio of the pure component $(y)$ previously determined as the mean amplitude ratio $\left(D_{a} / D_{b}\right)$ obtained from derivative spectra of pure $(y)$ at different concentration.

\section{Differential dual wavelength ( $\left.D^{1} D W L\right)$}

This novel method [33] was applied for the analysis of binary mixture $\mathrm{Y}$ and $\mathrm{Z}$ or ternary mixture $\mathrm{X}, \mathrm{Y}$ and $\mathrm{Z}$ using their derivative spectra at zero contribution of $X$ while the interference of the third one was eliminated by the difference between two points shows equal amplitudes on the mixture spectra.

This novel method was applied when the principle of the conventional dual-wavelength isn't fulfilled on the zero order absorption spectrum since no two points showing the equal absorbance of the interfering substance so it could be applied on the derivative spectrum with equal amplitudes of interfering substance.

The advantage of this novel method over conventional dual wavelength method that it applied on derivative spectrum of the mixture thus enhance resolution between peaks where the influence of one component in the mixtures either binary or ternary can be eliminated by applying derivative technique while the interference of the third one was eliminated by difference between two points shows equal amplitudes of the interfering substance on the mixture spectra.

\section{Differential derivative ratio (D'DR)}

A novel method [33] was applied for the analysis of ternary mixture after resolution using the derivative technique to resolve the severely overlapped spectra followed by differential derivative ratio method using derivative spectra instead of the zero order spectra in the conventional derivative ratio. This novel method was applied for the analysis of ternary mixtures where the zero order absorption spectra of cited components were severely overlapped, while the first derivative spectrum of two of them was overlapped at zero contribution of the third one. In the new approach, derivative ratio was applied using the first derivative spectra.

Differential derivative ratio method for the resolution of ternary mixtures had an advantage over derivative ratio method that it was more reliable with respect to utility and sensitivity without searching for the critical point either zero crossing point or coincident point for the separated peaks, the maximum amplitude of the separated peaks could be measured. In addition, D1DR overcame the main disadvantages of successive derivative ratio spectrophotometry for the analysis of ternary mixture that it required the use of multiple manipulating steps and multiple divisors.

\section{Successive derivative subtraction coupled with constant multiplication (SDS-CM)}

Lotfy et al. [34] introduced this method which could be applied for a ternary mixture of $\mathrm{X}, \mathrm{Y}$ and $\mathrm{Z}$, the zero order absorption spectra of cited components were severely overlapped while, their derivative spectra were partially overlapped where, derivative spectrum of $\mathrm{Z}$ was more extended than $Y$ which was in turn more extended than $X$. so we could eliminate them one by one using the derivative spectra of Z, Y respectively. The less extended component was determined through constant subtraction followed by constant multiplication, and so on. The concentration of each component was calculated using the regression equation representing the correlation between the peak to peak amplitudes of derivative spectra $\left(\mathrm{P}_{\max -\min }\right)$ versus the corresponding concentration of $\mathrm{X}, \mathrm{Y}$ and $\mathrm{Z}$. This method could be coupled with a step of the constant center method [23] namely, constant multiplication [18] and was applied for ternary [24] and binary mixtures [25].

\section{Derivative transformation (DT)}

This novel method [35] is applied in order to transform the derivative spectrum to its original zero order absorption spectrum. Dividing the obtained first derivative spectrum of $X$ by the derivative of normalized spectrum of pure $\mathrm{X}$ and multiplying the obtained spectrum or its amplitude (which is a constant represents its 
concentration) by the normalized spectrum of pure $X\left(a_{x}\right)$; the zero order absorption spectrum of $\mathrm{X}\left[\mathrm{a}_{\mathrm{X}} \mathrm{C}_{\mathrm{X}}\right]$ is obtained that could be used either for resolution or determination of $\mathrm{X}$. This can be formulated in the following equations:

$$
\begin{gathered}
(d / d \lambda)\left[a_{x} C_{x}\right] /(d / d \lambda)\left[a_{x}\right] \\
{\left[C_{x}\right] / *\left[a_{x}\right]} \\
{\left[a_{x} C_{x}\right]}
\end{gathered}
$$

These steps could be summarized by using a decoding spectrum $\left[a_{x}\right] /(d / d \lambda)\left[a_{x}\right]$ which is a new spectrum obtained by dividing the normalized spectrum by its derivative. After multiplying the derivative spectrum of $\mathrm{X}$ by the decoding spectrum; the original zero order absorption spectrum of $\mathrm{X}$ is obtained.

$$
\left[a_{x} C_{x}\right]=(d / d \lambda)\left[a_{x} C_{x}\right] /\left(\left[a_{x}\right] /(d / d \lambda)\left[a_{x}\right]\right)
$$

This decoding spectrum is the same for all the concentrations of pure X.

The reported applications of the previous novel methods based on derivative spectrophotometry are listed in table 2 .

\section{Method applied on the ratio spectra}

Recently several manipulating ratio spectra methods were developed for solving binary and ternary mixtures. The ratio spectra involve dividing the spectrum of the mixture by the standardized spectra of one analyte as a divisor. Several manipulating techniques were applied to ratio spectra as follows:

\section{Methods based on subtraction of the amplitudes of ratio spectra}

\section{Ratio subtraction method (RSM)}

This recently developed smart ratio subtraction method (RSM) [36] could be applied for the determination of several drugs in their binary mixtures without prior separation and has been applied for the determination of certain drugs in the presence of their degradation product. It based on the extension of zero order absorption spectrum of one of the components where the constants was measured at the extended part. The original spectrum of the less extended drug could be obtained after subtraction constant then multiplying the obtained spectrum by the divisor.

\section{Successive ratio subtraction (SRS)}

This method was recently adopted for the analysis of ternary mixture as successive ratio subtraction (SRS) [34]. If we have ternary mixture of $\mathrm{X}, \mathrm{Y}$ and $\mathrm{Z}$, where one of them is more extended than second, and consequently the third shows the more extended spectrum than both, so we can eliminate one of them by ratio subtraction, then the less extended drugs were determined as a binary mixture or eliminate them one by one using successive ratio subtractions and the less extended drug was determined at its maxima.

\section{Extended ratio subtraction method (EXRSM)}

Lotfy and Hegazy [37] introduced the extended ratio subtraction method (EXRSM) and it is successfully applied for the analysis of binary mixtures. It starts with the ratio subtraction method (RSM). To determine the second component (Y), an extension of the already developed method has been established as a new approach in which $\mathrm{Y}$ could be determined by dividing the obtained $\mathrm{D}_{0}$ spectrum of $\mathrm{X}$ by a known concentration of $X$ as a divisor $\left(X^{\prime}\right)$ to get the value that represents $\mathrm{X} / \mathrm{X}^{\prime}=$ constant. Dividing the spectrum of the mixture $(\mathrm{X}+\mathrm{Y})$ by the same divisor $\left(X^{\prime}\right)$, the division will give a new curve that represents $\mathrm{X} / \mathrm{X}^{\prime}+\mathrm{Y} / \mathrm{X}^{\prime}$ where $\mathrm{X} / \mathrm{X}^{\prime}$ is the previously obtained constant. If we subtract this constant, then multiply the obtained curve after subtraction by X' (the divisor), therefore we can obtain the zero order absorption spectrum $\left(D_{0}\right)$ of $Y$ (original spectrum of $Y$ ).

\section{Simultaneous ratio subtraction method (SRSM)}

The novel method [38] depends on that, if you have a mixture of two drugs $X$ and $Y$ having overlapped spectra, you can determine $X$ by dividing the spectrum of the mixture by a known concentration of
$\mathrm{Y}$ as a divisor $\left(\mathrm{Y}^{\prime}\right)$. The division will give a new curve that represents $\frac{X}{Y^{\prime}}+$ constant . If we measure this constant $\frac{Y}{Y^{\prime}}$ at the extended part, then new curve $\frac{X}{Y^{\prime}}$ obtained after subtraction the constant. The concentration of $\mathrm{X}$ or $\mathrm{Y}$ is calculated using the regression equation representing the correlation between the amplitudes of ratio spectra $\frac{X}{Y^{\prime}}$ or $\frac{X}{X^{\prime}}$ and the corresponding concentration of X or $\mathrm{Y}$ in $\mu \mathrm{g} / \mathrm{ml}$.

In addition, for obtaining the second component (Y), another extension of the already developed method has been established as a new approach in which Y could be determined by multiplication of $\mathrm{Y}^{\prime}$ divisor by the previously obtained constant. Therefore we can obtain the $\mathrm{D}^{\circ}$ curve of $\mathrm{Y}$ again.

The concentration of $\mathrm{Y}$ is calculated from the corresponding regression equation (obtained by plotting the absorbance values of the zero order curves of $\mathrm{Y}$ at its $\lambda_{\max }$ against the corresponding concentrations).

By selecting two wavelengths $\left(\lambda_{1}\right.$ and $\left.\lambda_{2}\right)$ on the obtained ratio spectrum and subtracting the amplitudes at these two points the constant $\mathrm{Y} / \mathrm{Y}^{\prime}$ will be cancelled along with any other instrumental error or any interference from the sample matrix.

The reported applications of the previous novel methods based on ratio subtraction are listed in table 3.

\section{Methods based on amplitude difference of the ratio spectra Ratio difference spectrophotometric method (RDSM)}

Lotfy and Hegazy [37] introduced the ratio difference spectrophotometric method (RDSM) and it is successfully applied for the analysis of binary and ternary mixtures after resolution, in which the amplitude difference between two points on the ratio spectra of a mixture is directly proportional to the concentration of the component of interest, where the independence of the interfering component is the basic principle of the ratio difference method.

\section{Constant center spectrophotometric method (CCSM)}

The constant center method [39] consisted of two steps complementary to each other namely constant calculation via amplitude difference method followed by constant multiplication. The first step constant calculation via amplitude difference method depends on that, if you had a mixture of two drugs $\mathrm{X}$ and $\mathrm{Y}$ having overlapped spectra, you could determine the two components X or $\mathrm{Y}$ separately by dividing the spectrum of the mixture by a known concentration of $\mathrm{X}$ or $\mathrm{Y}$ as a divisor. The zero order absorption spectrum of $X\left(D^{\circ}\right)$ or $Y\left(D^{\circ}\right)$ (original spectrum of $X$ or $Y$ ) could be obtained via the second step which called the constant multiplication step by multiplying the obtained constant value by the proper divisor. The concentration of X or Y could be calculated using its corresponding regression equation representing the linear relationship between the absorbance values of the zero order curves of cited drug at its $\lambda_{\max }$.

\section{Constant center coupled with spectrum subtraction (CC-SS)}

This novel approach [25] could be applied for binary mixture using one divisor for determination of $\mathrm{Y}$ by the previously described constant center method then the other component could be obtained by using spectrum subtraction method, by subtracting the obtained spectrum of $Y$ from the spectrum of the mixture $(X+Y)$ as, therefore we can obtain the $D^{\circ}$ spectrum of $X$ again. The concentration of $X$ is calculated from the corresponding regression equation obtained by plotting the absorbance values of the zero order absorption spectra of $X$ at its $\lambda$ max against the corresponding concentrations.

\section{Constant value via amplitude difference (CV-AD)}

This method which was a step in the constant center method [39] and center amplitude method [40]. It was applied successively as a novel method for the analysis of mixtures showing no spectrum extension to get the zero order absorption spectra of the cited drugs 
and it was recently applied to analyze the spectra of overlapped spectra progressively on the same ratio spectra. If we had a mixture of $\mathrm{X}, \mathrm{Y}$ and $\mathrm{Z}$, where $\mathrm{Y}$ and $\mathrm{Z}$ were severely overlapping and more extended than $\mathrm{X}$ so we could determine $\mathrm{Z}$ using mathematical techniques utilizing the constants. The concentration of $\mathrm{Z}$ was calculated using the regression equation representing the correlation between the amplitudes of ratio spectra $\mathrm{Z} / \mathrm{Z}^{\prime}$ and the corresponding concentration of $\mathrm{Z}$.

\section{Constant value (CV)}

The constant value method was one of the two complementary steps of constant center method [39] and it was recently used for the analysis of mixtures either binary or ternary mixtures based on the analysis of $\mathrm{Z}$ in the ternary mixture of $\mathrm{X}, \mathrm{Y}$ and $\mathrm{Z}$ where $\mathrm{Z}$ was more extended than $Y$ and $X$, on dividing with a divisor curve $Z^{\prime}$ a constant was obtained from the plateau region parallel to the $\mathrm{x}$-axis $\left(\mathrm{Z} / \mathrm{Z}^{\prime}\right)$. The concentration of $Z$ was calculated using the regression equation representing the correlation between the amplitudes of ratio spectra $\mathrm{Z} / \mathrm{Z}^{\prime}$ at extended region and the corresponding concentration of $\mathrm{Z}$ at zero contribution of $\mathrm{X}$ and $\mathrm{Y}$.

\section{Amplitude center method (ACM)}

The center amplitude method [40] depends on the progressive determination of three components in their ternary mixture through the same ratio spectrum via their corresponding amplitudes using single divisor. It consists of three stages complementary to each other namely; amplitude calculation, amplitude factor calculation and finally amplitude subtraction. Each of the mentioned methods was separately presented in previously reported spectrophotometric methods [30, 38, 39] which were applied for the analysis of binary mixtures only. Those three methods were combined together for the analysis of ternary mixtures for the first time under the name of center amplitude method. This novel method can be applied for a ternary mixture of $\mathrm{X}, \mathrm{Y}$ and $\mathrm{Z}$ with partially or severely overlapped spectra. i.e. at $\lambda_{1}$ and $\lambda_{2}, \mathrm{Y}$ and $\mathrm{Z}$ spectra shows certain overlapping with no contribution of $X$, while all spectra are overlapped spectra at $\lambda_{3}$.

The reported applications of the previous novel methods based on ratio amplitude difference are listed in table 4 .

\section{Method based on modulation of the amplitudes of ratio spectra}

\section{Amplitude modulation method (AM)}

The method is a novel manipulating ratio spectrum method $[13,14]$ using a normalized spectrum of the divisor obtained by dividing the certain spectrum of the component by its concentration. For a binary mixture, where one of its components is more extended than other one and the two components shows isoabsorption point at the zero spectrum and consequently retained as an isosbestic point at the ratio spectrum. Dividing the spectrum by the absorptivity curve of the extended component, the amplitude will be modulated to concentration.

\section{Advanced amplitude modulation method (AAM)}

This new extension (AAM) [8] can be applied for the analysis of severely overlapping spectra of binary mixtures and the two components shows isoabsorption point at the zero spectrum and consequently retained as an isosbestic point at the ratio spectrum. Two approaches can be adopted to calculate the concentrations of two components. The first approach can be obtained via mathematical calculation of the difference between isosbestic point (isoabsorption point in the ratio spectrum) and another point on the ratio spectrum then the iso-point regression equation could be used for the determination of both component.

The second approach adopted to calculate the concentrations of binary mixtures is done by coupling the amplitude modulation method together with the constant center method $[25,39,41]$. This approach starts with calculating the difference of ratio amplitudes of different concentrations of one component at two selected wavelengths; one of them is $\lambda_{\text {iso }}$ while the other is $\lambda_{2}$; where both spectra show overlap; using a normalized concentration of one as a divisor then the iso-point regression equation could be used for the determination of both component.

\section{Induced amplitude modulation method (IAM)}

Another approach concerning the same principle of the previously discussed amplitude modulation method is induced amplitude modulation [8] . This novel approach is introduced to calculate the concentrations of $\mathrm{X}$ and $\mathrm{Y}$ in their mixtures with severely or partially overlapping spectra, where $\mathrm{X}$ and $\mathrm{Y}$ either exhibit an isoabsorption point with low absorptivity or due to lack of isoabsorption point, which either causes error in the determination of concentrations using this point or hinder the application of amplitude modulation method $(A M)$ or advanced amplitude modulation method (AAM).

This novel method starts with the constant center method [25, 39, 41] through computing a regression equation representing the linear relationship between the difference of ratio amplitudes of different concentrations of pure $Y$ at two selected wavelengths; one of them is that with the highest amplitude value in the ratio spectrum $P_{\max }$ while the other is $\lambda_{2}$; where both spectra $\mathrm{X}$ and $\mathrm{Y}$ show overlap; using a normalized concentration of $\mathrm{X}^{\prime}$ as a divisor, versus the corresponding ratio amplitude of $Y$ at $\lambda_{\max }$.

The applications of the previous novel methods based on amplitude modulation are listed in table 5.

\section{Methods based on computed geometrical representation of amplitudes of ratio spectra}

\section{Geometrical amplitude modulation method (GAM)}

Lotfy et al. [22] introduced a new approach which is applied to determine the concentration of the minor component $\mathrm{X}$ in the presence of the major component $\mathrm{Y}$. It is based on the geometric representation of the effect of the standard addition of $X$ on the response of the binary mixture of $(\mathrm{X}$ and $\mathrm{Y})$, and the interpretation of this result as a regression equation. The method is a novel radio spectrum manipulating method using a normalized spectrum of the divisor obtained by dividing the certain spectrum of $Y^{\prime}$ component by its concentration.

\section{a) In case of component, $\mathrm{Y}$ is more extended than component $\mathrm{X}$}

By using the normalized spectrum of $\mathrm{Y}^{\prime}$ as a divisor, two points were selected in the overlapped region of the ratio spectra of X and Y (P1 and P2) were recorded. By calculating the difference $\Delta \mathrm{P}$ (P1 P2), the following equation was obtained:

$$
\Delta P=[\Delta a x / a y \cdot C x(\text { added })]+[\Delta a x / a y \cdot C x(\text { minor })]
$$

Where $\Delta \mathrm{aX}$ is equivalent to the difference of absorptivities of $\mathrm{X}$ component (aX1-aX2).

Practically, equation (4) can be mathematically obtained from the regression equation representing the linear geometric relationship between the differences of ratio amplitudes $(\Delta \mathrm{P})$ versus the added (X) concentration ( $\mathrm{CX}$ added):

$$
\left.\Delta P=\mathrm{M}_{1} . C x(\text { added })\right]+\mathrm{A}
$$

Where (M1) is the slope which is equal to $(\Delta a x / a y)$ and (A) is the intercept which is equal to [ $\Delta a x / a y . C x$ (minor) ].

So by the extrapolation of the linear geometric representation of $\Delta \mathrm{P}$ versus $\mathrm{Cx}$ added, the concentration of $\mathrm{CX}$ minor in mixture can be directly determined, through the following equation:

$$
A / M 1=C x(\text { minor })
$$

For the determination of major component $\mathrm{Y}$ [Cy major], amplitude modulation method is done through the direct recording of the constant value $\left(\mathrm{P}_{\text {const }}\right)$ using radio spectrum which is a straight line that is parallel to the wavelength axis in the region where $Y$ is extended.

b) In case of $X$ and $Y$ are showing severely overlapping spectra with an isosbestic point

By using the normalized spectrum of $Y$ as a divisor, two points are selected in the overlapped region of the ratio spectra of $X$ and $Y$ including the isosbestic point $\left(\mathrm{P}_{\text {iso }}\right.$ and $\left.\mathrm{P}_{2}\right)$ and the difference was calculated as follows: 


$$
\Delta P=[\Delta a x / a y \cdot C x(\text { added })]+[\Delta a x / \text { ay. } C x(\text { minor })]
$$

Where $\Delta \mathrm{aX}$ is equivalent to the difference of absorptivities of $\mathrm{X}$ component (aXiso - aX2).

By using the extrapolation of linear geometric representation of $\Delta P$ versus added $\mathrm{C}_{\mathrm{x}}, \mathrm{C}_{\mathrm{x}(\mathrm{minor})}$ in the mixture can be directly determined as shown before in the previous equations.

The extrapolation of linear geometric representation of $\mathrm{P}_{\text {iso }}$ versus added $C x$ will directly represent the sum of $(C x($ minor $)+C y)$, So $C y$ could be determined by difference between two extrapolations of linear geometric representation of $\mathrm{P}_{\text {iso }}$ and $\Delta \mathrm{P}(\mathrm{Piso}-\mathrm{P} 1)$ as summarized in the following equations:

$$
[C y]=B / M 2-A / M 1
$$

Where (M2) is the slope which is equal to $(a x / a y)$ and (B) is the intercept which is equal to [ $a x / a y$. $(C x$ (minor $)+C y]$.

\section{Geometrical induced amplitude modulation method (GIAM)}

The method [22] is an extension of the novel (GAM) using a normalized spectrum of the major component $Y^{\prime}$ as a divisor in order to determine minor component X. This method could be applied for a mixture of $\mathrm{X}$ and $\mathrm{Y}$ with severely overlapping spectra, where $\mathrm{X}$ and $\mathrm{Y}$ shows a large difference in their absorptivities, and hence no isoabsorption point exists at the zero spectrum. So the absorptivity factor is calculated for $\mathrm{X}$ and $\mathrm{Y}(\mathrm{aX} / \mathrm{aY}=\mathrm{F})[18,42]$. So instead, two wavelengths of the radio spectrum were selected $(P f$ and $P 2$ ) where $P f$ is the absorptivity factor point. By calculating the difference $\Delta P=P f-P 2$

$$
\Delta P=[\Delta a x / a y \cdot C x(\text { added })]+[\Delta a x / a y \cdot C x(\text { minor })]
$$

Where $\Delta \mathrm{aX}$ is equivalent to the difference of absorptivities of $\mathrm{X}$ component (aX1- aX2).

By calculating the extrapolation of linear geometric representation of $\Delta \mathrm{P}$ versus added $\mathrm{C}_{\mathrm{x}}, \mathrm{C}_{\mathrm{x}(\text { minor })}$ in the mixture can be directly determined as in GAM.

By calculating the difference between two extrapolations of $\left(\mathrm{P}_{\mathrm{f}}-\Delta \mathrm{P}\right)$ which is the difference between equations:

$$
B / M_{2}-{ }^{A} / M 1=\frac{1}{\mathrm{~F}}[\mathrm{Cy}]
$$

and then by multiply the obtain concentration by the absorptivity factor (F), the concentration of the major component $Y$ can be obtained as shown in the following equation:

$$
[C y]=B / M 2-A / M 1 * F
$$

Where and (M2) is the slope which is equal to $(a x / a y)$ and (B) is the intercept which is equal to $[a x / a y .(C x($ minor $)+C y]$. Since the measurements are done at at $\lambda_{\mathrm{f}}(\mathrm{aX} / \mathrm{aY}=\mathrm{F})$, so $\left(\mathrm{M}_{2}\right)$ will be equivalent to the absorptivity factor $(\mathrm{F})$, while $(\mathrm{B})$ will be equivalent to $[(F . C x$ (minor $)+C y($ major $)]$.

\section{Ratio H-point standard addition method (RHSAM)}

This method has the same theoretical background of the conventional H-point standard addition method which is done by plotting the absorbance at the two selected wavelengths versus the added analyte concentration $(\mathrm{X})$, where the interfering substance $(\mathrm{Y})$ exhibits the same absorbance, two straight lines are obtained that have a common point with coordinates $\mathrm{H}\left(-\mathrm{C}_{\mathrm{H}}, \mathrm{A}_{\mathrm{H}}\right)$, where $\mathrm{C}_{\mathrm{H}}$ is the unknown analyte concentration, and $A_{H}$ is the analytical signal due to the interferant $(\mathrm{Y})$. The method has been applied to binary mixtures of drugs with overlapped absorption spectra [43-45] .

By introducing a new modification which is using the normalized spectrum of $(Y)$ as the divisor $[31,46]$, the determination of both components $(\mathrm{X})$ and $(\mathrm{Y})$ is done using the peak amplitudes of the ratio spectra at any two wavelengths along the ratio spectra to be plotted versus the added concentrations of component (X), and the two straight lines obtained will intercept at the so-called RH point having $\left(-\mathrm{C}_{\mathrm{RH}} ; \mathrm{P}_{\mathrm{RH}}\right)$, where $\mathrm{C}_{\mathrm{RH}}$ is the unknown analyte concentration
$(C x)$ and $\mathrm{P}_{\mathrm{RH}}$ is equivalent to the concentration of interfering component $(C y)$. The concentrations of $\mathrm{X}$ and $\mathrm{Y}$ can be calculated mathematically through the following equations:

$$
\begin{gathered}
C x=(B-A) /(M 1-M 2) \\
C y=(M 1 B-M 2 A) /(M 1-M 2)
\end{gathered}
$$

Where $M_{1}$ and $M_{2}$ are the slopes of the standard addition calibration lines obtained on applying the RHPSAM at $\lambda_{1}$ and $\lambda_{2}$, respectively; A and $\mathrm{B}$ are the intercepts of the two regressions, such that $\mathrm{A}=$ $\left(\mathrm{X} / \mathrm{Y}^{\prime}\right)_{1+}\left(\mathrm{Y} / \mathrm{Y}^{\prime}\right)$ and $\mathrm{B}=\left(\mathrm{X} / \mathrm{Y}^{\prime}\right)_{2+}\left(\mathrm{Y} / \mathrm{Y}^{\prime}\right)$.

The applications of the previous novel methods based on computed geometrical representations are listed in table 6.

\section{Methods based on mean centering of amplitudes of ratio spectra}

Mean centering of ratio spectra method [47-49] in which both binary and ternary mixtures could be determined without previous separation. In this method the ratio spectra are obtained after which the constant is removed by mean centering of the ratio spectra, while for the ternary mixture an extra step was performed where the mean centered ratio spectra is further divided by the mean centered vector of the other two components, then the second ratio spectra was mean centered.

\section{Mean centering using the geometric mean}

A new approach was applied [50] where data transformation in mean centering of ratio spectra method was done using the geometric mean rather than the arithmetic mean which is a better measure of central tendency, and this was done by taking the logarithm of each data point.

\section{Pure component contribution algorithm (PCCA)}

Another novel approach namely, pure component contribution algorithm (PCCA) was described for extracting components' contribution from severely overlapped signals [51] . It is based on the development of a code function which eliminates the signal of interfering components using mean centering as a processing tool; finally, the pure contribution of each component is extracted. The algorithm allows the determination of each component as a single one.

\section{Continuous wavelet transform (CWT)}

Another different aspect of ratio manipulation is wavelet transform. It is a very powerful recent tool in signal processing. It is similar to fourier transform with the advantage of having many basic functions called wavelets while the basic functions in fourier transform are the trigonometric functions (sine and cosine). Continuous wavelet transform (CWT) has been used over the past decade in many areas like de-noising, smoothing, data compression and quantitative analysis of multicomponent systems [52-54] . Due to the presence of a large number of basic wavelets, wavelet transform provides a solution for almost all chemistry problems with one or more of its wavelets by choosing the suitable scaling parameter.

The applications of the previous novel methods based on mean centering and wavelet transformation are listed in table 7.

The application of each of the previous methods requires certain conditions. The methods can be applicable or not according to the nature of the components' spectral profiles. The advantages and limitations of each method were listed in Tables 8-10.

\section{CONCLUSION}

The last decade (2006-2016) witnessed the most remarkable development in the field of ultraviolet (UV) spectroscopy. The incorporation of the mathematical calculations leads to discovering new pathways for the application of UV spectroscopy in the field of analysis. At the beginning of this decade, mainly derivative spectrophotometry was commonly used; but through this $10 \mathrm{y}$, different manipulating spectrophotometric techniques were 
established and the recent UV spectrophotometric techniques were found. The proposed methods are timesaving, economical and environmentally friendly since no chemical reagents or harmful organic solvents were used. Compared to the conventional reported spectrophotometric methods for this mixture, the proposed method is advantageous regarding simplicity of operation and sensitivity of measurement. The developed methods do not require elaborate treatment, sophisticated experimental steps or consumption of organic solvents usually associated with
HPLC and HPTLC methods of analysis; however, the developed methods have the specific advantage of separation methods and obviously can be applied in complex mixtures with partially and severely overlapped spectra. The applicability of the developed methods was evaluated through the determination of this drug combination in pharmaceutical formulations with good accuracy and precision; therefore, it can be excellent alternatives to other hyphenated analytical techniques.

Table 1: Examples for applications of methods based zero order absorption spectra

\begin{tabular}{|c|c|c|}
\hline Method & Applications & Ref \\
\hline Induced dual wavelength (IDW) & Hydrocortisone acetate and Fusidic acid. & [8] \\
\hline Dual wavelength resolution technique (DWRT) & Hydrocortisone acetate and Fusidic acid. & [8] \\
\hline \multirow[t]{4}{*}{ Absorption factor method (AFM) } & Ramipril and Olmesartan medoxomil. & [12] \\
\hline & Simvastatin and Ezetimibe. & [38] \\
\hline & Sodium cromoglicate and fluorometholone. & [42] \\
\hline & Celecoxib and Diacerein. & [55] \\
\hline \multirow[t]{8}{*}{ Absorbance subtraction (AS) } & Chloramphenicol, dexamethasone sodium phosphate and tetryzoline $\mathrm{HCl}$ & [14] \\
\hline & Timolol maleate and dorzolamide & [13] \\
\hline & Amlodipine, Hydrochlorothiazide and Valsartan & [56] \\
\hline & Paracetamol and dantrolene sodium & [57] \\
\hline & Esomeprazole magnesium trihydrate and Naproxen & [58] \\
\hline & Mebeverine $\mathrm{HCl}$ and chlordiazepoxide & [35] \\
\hline & Moexipril hydrochloride and hydrochlorothiazide & [59] \\
\hline & Flucloxacillin and amoxicillin & [60] \\
\hline Advanced absorbance subtraction (AAS) & Chloramphenicol and prednisolone acetate & [17] \\
\hline Absorptivity factor method & Salmeterol xinafoate and Fluticasone propionate & [18] \\
\hline \multirow[t]{3}{*}{ (a-factor) } & Sodium cromoglicate and fluorometholone. & [42] \\
\hline & Amlodipine, Valsartan and Hydrochlorothiazide & [56] \\
\hline & Perindopril arginine and amlodipine besylate & [61] \\
\hline Area under the curve correction method (AUC-CM) & Ofloxacin, prednisolone acetate and tetryzoline $\mathrm{HCl}$. & [19] \\
\hline \multirow[t]{2}{*}{ Compensated area under the curve method (CAUC) } & Prednisolone acetate and tetryzoline $\mathrm{HCl}$. & [22] \\
\hline & Sodium cromoglicate and tetryzoline $\mathrm{HCl}$. & [22] \\
\hline \multirow[t]{6}{*}{ Spectrum subtraction (SS) } & Beclomethasone dipropionate and salbutamol & [25] \\
\hline & lidocaine $\mathrm{HCl}$, flucortolone pivalate and chlorquinaldol & [33] \\
\hline & Betamethasone valerate and fusidic acid & [62] \\
\hline & Chloramphenicol and prednisolone acetate & [17] \\
\hline & Omeprazole, Tinidazole and Doxycycline & [63] \\
\hline & Mebeverine $\mathrm{HCl}$ and chlordiazepoxide & [35] \\
\hline
\end{tabular}

Table 2: Examples for applications of methods based on derivative spectra

\begin{tabular}{|c|c|c|}
\hline Method & Applications & Ref \\
\hline \multirow[t]{2}{*}{ Amplitude subtraction (AS) } & Sitagliptin phosphate and metformin $\mathrm{HCl}$ & [64] \\
\hline & Lidocaine $\mathrm{HCl}$, Calcium Dobesilate, and Dexamethasone Acetate & [30] \\
\hline \multirow[t]{2}{*}{ Modified amplitude subtraction (MAS) } & Sitagliptin phosphate and metformin $\mathrm{HCl}$ & [64] \\
\hline & Lidocaine $\mathrm{HCl}$, Calcium Dobesilate, and Dexamethasone Acetate & [30] \\
\hline \multirow{4}{*}{ Amplitude factor (P-factor) } & Lidocaine $\mathrm{HCl}$, Calcium Dobesilate, and Dexamethasone Acetate & [30] \\
\hline & $\begin{array}{l}\text { Chloramphenicol, dexamethasone sodium phosphate and } \\
\text { tetryzoline } \mathrm{HCl}\end{array}$ & [14] \\
\hline & Sitagliptin phosphate and metformin $\mathrm{HCl}$ & [64] \\
\hline & Omeprazole, Tinidazole and Doxycycline & [63] \\
\hline \multirow[t]{2}{*}{ Amplitude summation method (A-Sum) } & $\begin{array}{l}\text { Chloramphenicol, dexamethasone sodium phosphate and } \\
\text { tetryzoline } \mathrm{HCl}\end{array}$ & [14] \\
\hline & Ascorbic acid and rutin. & [65] \\
\hline \multirow[t]{2}{*}{ Simultaneous derivative ratio spectrophotometry $\left(S^{1} D D\right)$} & Orphenadrine and Paracetamol & [31] \\
\hline & Dimenhydrinate and Cinnarizine & [66] \\
\hline Modified Graphical method via Regression Equation & Sodium cromoglicate andxylometazoline $\mathrm{HCl}$ & [24] \\
\hline Differential dual wavelength ( $\left.D^{1} D W L\right)$ & lidocaine $\mathrm{HCl}$, fluocortolone pivalate and chlorquinaldol. & [33] \\
\hline Differential derivative ratio $\left(D^{1} D R\right)$ & lidocaine $\mathrm{HCl}$, flucortolone pivalate and chlorquinaldol. & [33] \\
\hline Successive derivative subtraction coupled with constant multiplication & lidocaine $\mathrm{HCl}$, calcium dobesilate and dexamethasone acetate & [34] \\
\hline \multirow[t]{3}{*}{$(S D S-C M)$} & $\begin{array}{l}\text { Chloramphenicol, dexamethasone sodium phosphate and } \\
\text { tetryzoline } \mathrm{HCl}\end{array}$ & {$[40]$} \\
\hline & lidocaine $\mathrm{HCl}$, flucortolone pivalate and chlorquinaldol. & [33] \\
\hline & chloramphenicol and dexamethasone sodium phosphate & [67] \\
\hline Derivative transformation (DT) & Mebeverine hydrochloride andchlordiazepoxide & [35] \\
\hline
\end{tabular}


Table 3: Examples for applications of methods based on subtraction of the amplitudes of ratio spectra

\begin{tabular}{|c|c|c|}
\hline Method & Applications & Ref \\
\hline \multirow[t]{23}{*}{ Ratio subtraction method (RSM) } & Vincamine in the presence of its acid degradation product. & [36] \\
\hline & Cinnarizine and nicergoline. & [36] \\
\hline & Almitrine dismesylate and raubasine. & [68] \\
\hline & Metronidazole and diloxanide furoate. & [15] \\
\hline & Moexipril hydrochloride and hydrochlorothiazide. & [69] \\
\hline & Fosinopril and hydrochlorothiazide. & [69] \\
\hline & Irbesartan and hydrochlorothiazide & [70] \\
\hline & Fluconazole in the presence of its oxidative degradation product & [71] \\
\hline & Ofloxacin and Dexamethasone & [72] \\
\hline & Cefepime hydrochloride in the presence of its acid and alkaline degradation products & [73] \\
\hline & Ezetimibe and Atorvastatin Calcium & [74] \\
\hline & Metoclopramide hydrochloride and paracetamol. & [75] \\
\hline & Olmesartan, Amlodipine and Hydrochlorothiazide. & [76] \\
\hline & Perindopril and Indapamide. & [77] \\
\hline & Timolol maleate and dorzolamide hydrochloride. & [13] \\
\hline & Hydrochlorothiazide and Amiloride hydrochloride & [78] \\
\hline & Tiemonium methyl sulphate in the presence of its acid degradate & [79] \\
\hline & Naproxen Sodium and Domperidone Maleate & [80] \\
\hline & Ciprofloxacin hydrochloride and dexamethasone sodium phosphate & [81] \\
\hline & Ambroxol hydrochloride and doxycycline & [82] \\
\hline & Domperidone and Ranitidine & [83] \\
\hline & Cefixime Trihydrate in the Presence of its Acid and Alkali Degradation products & [84] \\
\hline & Ascorbic Acid and Rutin & [65] \\
\hline \multirow[t]{4}{*}{ Successive ratio subtraction (SRS) } & Lidocaine $\mathrm{HCl}$, calcium dobesilate and dexamethasone acetate & [34] \\
\hline & $\begin{array}{l}\text { Hydroquinone, tretinoin, hydroquinone degradation, } 1,4 \text { benzoquinone and } \\
\text { methylparaben. }\end{array}$ & [85] \\
\hline & Lidocaine hydrochloride, flucortolone pivalate and chlorquinaldol. & [33] \\
\hline & Lidocaine $\mathrm{HCl}$, calcium dobesilate and dexamethasone acetate & [30] \\
\hline \multirow[t]{14}{*}{ Extended ratio subtraction method (EXRSM) } & Omeprazole, Tinidazole and clarithromycin & [37] \\
\hline & Sodium cromoglicate and Fluorometholone & [41] \\
\hline & Chlorphenoxamine $\mathrm{HCl}$ and caffeine & [86] \\
\hline & Timolol maleate and dorzolamide $\mathrm{HCl}$ & [13] \\
\hline & Ciprofloxacin $\mathrm{HCl}$ and Hydrocortisone & [16] \\
\hline & mebeverine $\mathrm{HCl}$ and chlordiazepoxide & [35] \\
\hline & Methocarbamol and Paracetamol & [87] \\
\hline & Lidocaine hydrochloride, flucortolone pivalate and chlorquinaldol. & [33] \\
\hline & Moexipril and Hydrochlorothiazide & [88] \\
\hline & Simvastatin and ezetimibe & [38] \\
\hline & Allopurinol (ALP) and BenzbromaroneAllopurinol (ALP) and Benzbromarone & [89] \\
\hline & Allopurinol and Benzbromarone & \\
\hline & SimvasStatin (SM) andS & [89] \\
\hline & Simvastatin and Sitagliptin & \\
\hline \multirow[t]{3}{*}{ Simultaneous ratio subtraction method (SRSM) } & Simvastatin and ezetimibe & [38] \\
\hline & Timolol maleate and dorzolamide $\mathrm{HCl}$ & [13] \\
\hline & Domperidone and Ranitidine & [83] \\
\hline
\end{tabular}

Table 4: Examples for applications of methods based amplitude difference of ratio spectra

\begin{tabular}{|c|c|c|}
\hline Method & Applications & Ref \\
\hline Ratio difference spectrophotometric method (RDSM) & $\begin{array}{l}\text { Omeprazole, Tinidazole and clarithromycin } \\
\text { Retinoic acid and hydroquinone } \\
\text { Brimonidine tartarate and timolol maleate } \\
\text { Sodium cromoglicate and Fluorometholone } \\
\text { Ciprofloxacin } \mathrm{HCl} \text { and Hydrocortisone } \\
\text { Ofloxacin and Dexamethasone } \\
\text { Chlorphenoxamine } \mathrm{HCl} \text { and caffeine } \\
\text { Timolol and dorzolamide } \\
\text { Fluconazole in the presence of its oxidative degradation product } \\
\text { Hydrochlorothiazide and amiloride HCl } \\
\text { Naproxen Sodium and Domperidone Maleate } \\
\text { Ciprofloxacin hydrochloride and dexamethasone sodium phosphate } \\
\text { Ascorbic Acid and Rutin } \\
\text { Simvastatin and ezetimibe } \\
\text { Rabeprazole sodium and Domperidone } \\
\text { Itopride HCl and Rabeprazole sodium } \\
\text { Chlorpheniramine maleate, Pseudoephedrine HCl and Ibuprofen } \\
\text { Cefprozil and its alkaline-induced degradation product } \\
\text { Cinnarizine and dimenhydrinate } \\
\text { Flumethasone pivalate and clioquinol } \\
\text { Irbesartan and Hydrochlorothiazide }\end{array}$ & $\begin{array}{l}{[37]} \\
{[90]} \\
{[91]} \\
{[92]} \\
{[16]} \\
{[72]} \\
{[86]} \\
{[13]} \\
{[71]} \\
{[78]} \\
{[80]} \\
{[81]} \\
{[65]} \\
{[38]} \\
{[93]} \\
{[94]} \\
{[95]} \\
{[96]} \\
{[97]} \\
{[98]} \\
{[99]}\end{array}$ \\
\hline
\end{tabular}


Constant center spectro-photometric method (CCSM)

Constant center coupled with spectrum subtraction (CC-SS)

Constant value via amplitude difference ( $C V-A D)$

Constant value (CV)

Amplitude center method (ACM)
Buflomedil in Presence of its Acid Induced Degradation Products

Chloramphenicol and dexamethasone sodium phosphate

Ibuprofen and famotidine

Paracetamol and dantrolene sodium

Gemifloxacin in presence of its acid degradation products.

Chloramphenicol and prednisolone acetate

Nicardipine in the presence of its alkaline degradation products

Esomeprazole magnesium trihydrate and Naproxen

Cefquinome sulfate in the presence of its degradation products

Diatrizoate sodium in the presence of its acidic degradation product

Itraconazole in the presence of Its Oxidative Degradation

Trimethoprim, Sulphamethoxazole and Oxytetracycline

Antazoline $\mathrm{HCl}$ and Tetryzoline $\mathrm{HCl}$

Sodium cromoglicate and oxymetazoline $\mathrm{HCl}$

Simvastatin and ezatimibe

Sodium cromoglicate and Fluorometholone

Rabeprazole sodium and Domperidone

Irbesartan and Hydrochlorothiazide

Itopride $\mathrm{HCl}$ and Rabeprazole sodium

Cinnarizine and dimenhydrinate

Chloramphenicol and prednisolone acetate

Betamethasone valerate and fusidic acid

Amlodipine besylate and atenolol

Diflucortolone valerate and isoconazole nitrate

Omeprazole, Tinidazole and Doxycycline

Beclomethasone dipropionate and salbutamol

lidocaine hydrochloride, flucortolone pivalate in presence of chlorquinaldol

lidocaine hydrochloride, flucortolone pivalate in presence of chlorquinaldol

mebeverine $\mathrm{HCl}$ and chlordiazepoxide

Chloramphenicol, dexamethasone sodium phosphate and tetryzoline $\mathrm{HCl}$.

Amlodipine, Valsartan and Hydrochlorothiazide
[100]

[67]

[101]

[57]

[102]

[17]

[103]

[58]

[104]

[105]

[106]

[107]

[108]

Table 5: Examples for applications of methods based on modulation of the amplitudes of ratio spectra

\begin{tabular}{|c|c|c|}
\hline Method & Applications & Ref \\
\hline \multirow[t]{7}{*}{ Amplitude modulation (AM) } & Simvastatin and ezetimibe & [112] \\
\hline & Timolol and dorzolamide & [13] \\
\hline & Chloramphenicol, dexamethasone sodium phosphate and tetryzoline $\mathrm{HCl}$. & [14] \\
\hline & Flucloxacillin and amoxicillin & [60] \\
\hline & Mebeverine $\mathrm{HCl}$ and chlordiazepoxide & [35] \\
\hline & Paracetamol and dantrolene sodium & [57] \\
\hline & Orphenadrine and Paracetamol & [31] \\
\hline \multirow[t]{2}{*}{ Advanced amplitude modulation (AAM) } & Hydrocortisone acetate and Fusidic acid & [8] \\
\hline & Chloramphenicol and prednisolone & [17] \\
\hline \multirow[t]{2}{*}{ Induced amplitude modulation (IAM) } & Hydrocortisone acetate and Fusidic acid & [8] \\
\hline & Sitagliptin phosphate and metformin $\mathrm{HCl}$ & [64] \\
\hline
\end{tabular}

Table 6: Examples for applications of methods based on computed geometrical representation

\begin{tabular}{|c|c|c|}
\hline Method & Applications & Ref \\
\hline \multirow[t]{2}{*}{ Geometrical amplitude modulation (GAM) } & Prednisolone acetate and tetryzoline $\mathrm{HCl}$. & [22] \\
\hline & Sodium cromoglicate and tetryzoline $\mathrm{HCl}$. & [22] \\
\hline Geometrical induced amplitude modulation (GIAM) & Sodium cromoglicate and tetryzoline $\mathrm{HCl}$. & [22] \\
\hline \multirow[t]{5}{*}{ Ratio H-point standard addition method (RHSAM) } & Itopride hydrochloride and pantoprazole sodium & [46] \\
\hline & Orphenadrine and Paracetamol & [31] \\
\hline & Dimenhydrinate and Cinnarizine & [66] \\
\hline & Prednisolone acetate and tetryzoline $\mathrm{HCl}$. & [22] \\
\hline & Sodium cromoglicate and tetryzoline $\mathrm{HCl}$. & [22] \\
\hline
\end{tabular}

Table 7: Examples for applications of methods based on mean centering and wavelet transformation

\begin{tabular}{|c|c|c|}
\hline Method & Applications & Ref \\
\hline Mean centering using geometric mean & Aspirin, atorvastatin and clopidogrel & [50] \\
\hline Pure component contribution algorithm (PCCA) & Amiloride $\mathrm{HCl}$, Atenolol and Hydrochlorothiazide & [51] \\
\hline \multirow[t]{6}{*}{ Continuous wavelet transform (CWT) } & Phospho-and silico-molybdenum blue complexes & [52] \\
\hline & levodopa-benserazide tablets & [54] \\
\hline & Cefoperazone and sulbactam & [113] \\
\hline & Cefprozil in the presence of its alkaline-induced degradation product & [96] \\
\hline & Amlodipine, Aliskiren and Hydrochlorothiazide & [114] \\
\hline & Paracetamol and caffeine & [115] \\
\hline
\end{tabular}


Table 8: Advantages and limitations of methods based zero order absorption spectra

\begin{tabular}{|c|c|}
\hline Method & Advantages \\
\hline $\begin{array}{l}\text { Induced dual } \\
\text { wavelength }(I D W)\end{array}$ & $\begin{array}{l}\text { - Can be applied when the conventional dual-wavelength } \\
\text { method fails. } \\
\text { - Minimum manipulation using the zero order absorption (no } \\
\text { divisor) } \\
\text { - By choosing } \lambda_{\max } \text { in the manipulation steps the absorbance } \\
\text { difference values will be enhanced, which increases the sensitivity } \\
\text { of the method. }\end{array}$ \\
\hline $\begin{array}{l}\text { Dual wavelength } \\
\text { resolution technique } \\
(D W R T)\end{array}$ & $\begin{array}{l}\text { - Recovering the original spectra of the cited drugs which act as } \\
\text { the spectral profile of them. } \\
\text { - Enhances the sensitivity of the results using measurements at } \\
\text { peak maxima. }\end{array}$ \\
\hline $\begin{array}{l}\text { Absorption correction } \\
\text { method (ACM) }\end{array}$ & $\begin{array}{l}\text { - The concentrations of } \mathrm{X} \text { and } \mathrm{Y} \text { components can calculate } \\
\text { through a simple equation at } \lambda \max \text {. }\end{array}$ \\
\hline $\begin{array}{l}\text { Absorbance } \\
\text { subtraction }(A S)\end{array}$ & $\begin{array}{l}\text { - No need for a complementary spectrophotometric method to } \\
\text { measure the concentration of one of the components. } \\
\text { - Both components can be determined using unified regression } \\
\text { equation at } \lambda_{\text {iso. }}\end{array}$ \\
\hline $\begin{array}{l}\text { Advanced absorbance } \\
\text { subtraction }(A A S)\end{array}$ & $\begin{array}{l}\text { - Can be applied for severely overlap spectra } \\
\text { - No need for a complementary method to measure the } \\
\text { concentration of one of the components. } \\
\text { - Both components can be determined using unified regression } \\
\text { equation at } \lambda_{\text {iso. }}\end{array}$ \\
\hline $\begin{array}{l}\text { Absorptivity factor } \\
\text { method } \\
\text { (a-factor) }\end{array}$ & $\begin{array}{l}\text { - Can be applied where there is a large difference in the } \\
\text { absorptivity between both components in a mixture so that no } \\
\text { isoabsorption point occurs. } \\
\text { - The spectral measurements are done at zero order to obtain } \\
\text { maximum accuracy and reproducibility. }\end{array}$ \\
\hline $\begin{array}{l}\text { Area under the curve } \\
\text { correction method } \\
(\text { AUC-CM) }\end{array}$ & $\begin{array}{l}\text { - Enhances the sensitivity, compared to absorption correction } \\
\text { method, as the values of AUC is relatively higher than absorbance } \\
\text { value for the same component, even in lower concentrations. } \\
\text { - Simpler than conventional AUC method as there is no need for } \\
\text { Cramer's rule. }\end{array}$ \\
\hline $\begin{array}{l}\text { Compensated area } \\
\text { under the curve } \\
\text { method (CAUC) }\end{array}$ & $\begin{array}{l}\text { - Determination of minor component in the presence of major } \\
\text { one. } \\
\text { - Providing better sensitivity and prevailing over the } \\
\text { instrumental noise. }\end{array}$ \\
\hline $\begin{array}{l}\text { Spectrum subtraction } \\
\text { (SS) }\end{array}$ & $\begin{array}{l}\text { - The zero order } \mathrm{D}_{0} \text { spectrum of the second component }(\mathrm{Y}) \text { is } \\
\text { obtained through one step. }\end{array}$ \\
\hline
\end{tabular}

Limitations

- Calculation of the equality factor (F).

- The selection of optimum 2 wavelengths.

- Must be used in complementary to another spectrophotometric method such as conventional dual wavelength, induced dual wavelength...

- Only applied to mixture of $X+Y$, where $Y$ shows interference at $\lambda_{\max }$ of $X\left(\lambda_{1}\right)$, while $X$ shows no interference with $Y$ at $\left(\lambda_{2}\right)$.

- Calculating absorption factor of pure Y.

- The existence of isoabsorptive point of both components and the extension of the spectra of one component are a must.

- Increased risk of error in calculating the absorption factor in the case of low concentrations.

- The existence of isoabsorption point of both components is a must.

- Increased risk of error in calculating the absorption factor in the case of low concentrations.

- It can be only applied for mixtures where one of its components can be measured singly without any interference.

- Requires the spectral extension of one component over the other one.

- Multiple steps as it require several runs for each prepared mixture using different concentrations of the minor component in the reference cell.

- Applied only as a complementary method where the zero order $\mathrm{D}^{\circ}$ spectrum of the first component $(\mathrm{X})$ is obtained.

Table 9: Advantages and limitations of methods based on derivative spectra

\begin{tabular}{|c|c|c|}
\hline Method & Advantages & Limitations \\
\hline Amplitude subtraction (AS) & - Simple (one step). & $\begin{array}{l}\text { - Critical measurements of the amplitudes at the } \\
\text { selected wavelength. } \\
\text { - Greatly affected by wavelength increment. } \\
\text { - The high noise which affects the signal to noise } \\
\text { ratio. } \\
\text { - Only applied for partially overlapped spectra of } \\
\text { X and Y. }\end{array}$ \\
\hline $\begin{array}{l}\text { Modified amplitude subtraction } \\
\text { (MAS) }\end{array}$ & $\begin{array}{l}\text { - Can be applied for severely overlapped spectra of X } \\
\text { and Y. }\end{array}$ & $\begin{array}{l}\text { - Critical measurements of the amplitudes at the } \\
\text { selected wavelength. } \\
\text { - Greatly affected by wavelength increment. } \\
\text { - The high noise which affects the signal to noise } \\
\text { ratio. }\end{array}$ \\
\hline Amplitude factor (P-factor) & - Simple (one step). & $\begin{array}{l}\text { - Critical measurements of the amplitudes at the } \\
\text { selected wavelength. } \\
\text { - Greatly affected by wavelength increment. } \\
\text { - The high noise which affects the signal to noise } \\
\text { ratio. } \\
\text { - Only applied for partially overlapped spectra of } \\
\text { X and Y. }\end{array}$ \\
\hline $\begin{array}{l}\text { Amplitude summation method (A- } \\
\text { Sum) }\end{array}$ & $\begin{array}{l}\text { - The shift that occurs for the isosbestic point in } \\
\text { derivative spectra may lead to correction of the } \\
\text { interference that may originate from excipients. }\end{array}$ & $\begin{array}{l}\text { - Critical measurements of the amplitudes at the } \\
\text { selected wavelength. } \\
\text { - Greatly affected by wavelength increment. }\end{array}$ \\
\hline
\end{tabular}


Simultaneous derivative ratio spectrophotometry ( $\left.S^{1} D D\right)$

Derivative compensation ratio via regression equation

\section{Differential dual wavelength (D'DWL)}

Differential derivative ratio $\left(D^{1} D R\right)$

Successive derivative subtraction coupled with constant multiplication (SDS-CM)

Derivative transformation (DT)
- The normalized spectrum of the divisor is used and hence no need for the tedious step of choosing the optimum concentration of divisor.

- Simpler than graphical method and lower risk of error.

- Applied when the principle of the conventional dualwavelength isn't fulfilled on the zero order absorption spectrum.

- Used for the analysis of the ternary mixture using single divisor without searching the critical point at the separated peaks.

- The $\mathrm{D}^{1}$ spectrum of each component in the mixture was obtained as that of pure one without any interference from other components in the mixture.

- Higher amplitudes values and subsequently larger slope and maximum sensitivity in contrary to those obtained by applying derivative technique

- Transform first order spectrum into zero order absorption spectra by their corresponding decoding spectra.

- High accuracy, reproducibility, sensitivity and

ensures the spectrum typical to that of a pure form in its spectral profile.
- The high noise which affects the signal to noise ratio.

- Greatly affected by wavelength increment.

- The high noise which affects the signal to noise ratio.

- Multiple steps and time consuming.

- Requires the spectral extension of one

component over the other one.

- Critical measurements of the amplitudes at the selected wavelength.

- Greatly affected by wavelength increment.

- Affected by wavelength increment.

- Limited for ternary mixtures of X, Y and Z, where the D spectrum of $\mathrm{Z}$ is more extended than $\mathrm{Y}$ which was in turn more extended than X.

- The need of a different divisor for each component and utilizing different ratio spectra.

- Used complementary to derivative spectrophotometric methods.

Table 10: Advantages and limitations of methods based on ratio spectra

\begin{tabular}{ll}
\hline Method & Advantages \\
\hline Ratio subtraction & $\bullet$ It is able to determine the component of interest at its $\lambda_{\max }$ \\
method (RSM) & (the spectral measurements are done at zero order to obtain \\
& maximum accuracy and reproducibility). \\
& $\bullet \quad$ Obtain spectra typical to that of pure components which \\
& confirm the spectral profile of each component of interest. \\
& $\bullet \quad$ No need for special software.
\end{tabular}

Successive ratio subtraction (SRS)

- Applied for mixtures of more than 2 components.

- Same advantages of RS method.

Extended ratio subtraction method (EXRSM)

Simultaneous ratio subtraction method (SRSM)

Ratio difference spectrophotometric method (RDSM)

Constant center spectrophotometric method (CCSM) multiplication by the divisor step)
- It is able to determine both extended and non-extended components.

- It is able to determine both components at its $\lambda_{\max }$ (at zero order to obtain maximum accuracy and reproducibility).

- Obtain spectra typical to that of pure components which confirm the spectral profile of each component of interest.

- No need for special software.

- It is able to determine both extended and non-extended components.

- Direct determination through amplitude calculation (No

- No need for special software.

- Simple, no need for special software.

- Complete elimination of the interfering component in the form of constant (difference at any two points will be equal to zero), no need for critical measurements which leads to reproducible and robust results.

- Reduced manipulating steps (eliminates the step of derivative calculation, so signal to noise ratio is enhanced)

- The spectral measurements are done at zero order to obtain maximum accuracy and reproducibility.

- Obtain spectra typical to that of pure components which confirm the spectral profile of each component of interest.

- Maximum simplicity, as there is no need for special

software.

- It's not limited to analysis of mixtures with extended

\section{Limitations}

- Applied only for binary mixtures.

- Determination of the non-extended component only.

- Upon analysis of mixtures containing low concentrations of the extended component, where the calculation of the constant value through plateau region was inaccurate due to low signal to noise ratio, which resulted in inaccurate recovery percentages for both components in the mixtures.

- Upon analysis of mixtures containing low concentrations of the extended component, where the calculation of the constant value through plateau region was inaccurate due to low signal to noise ratio, which resulted in inaccurate recovery percentages for both components in the mixtures.

- Upon analysis of mixtures containing low concentrations of the extended component, where the calculation of the constant value through plateau region was inaccurate due to low signal to noise ratio, which resulted in inaccurate recovery percentages for both components in the mixtures.

- Upon analysis of mixtures containing low concentrations of the extended component, where the calculation of the constant value through plateau region was inaccurate due to low signal to noise ratio, which resulted in inaccurate recovery percentages for both components in the mixtures.

- Results are expressed in amplitude ratio spectra (not zero order absorption).

- Standard solutions of the interfering substance should be present to act as a divisor.

- The choice of the divisor is critical to maximizing sensitivity and minimize noise.

- Additional step then (RSM and RS-EXRSM) which is the construction of one linear regression for $[\mathrm{P}$ recorded $\mathrm{P}$ postulated] for each drug. 


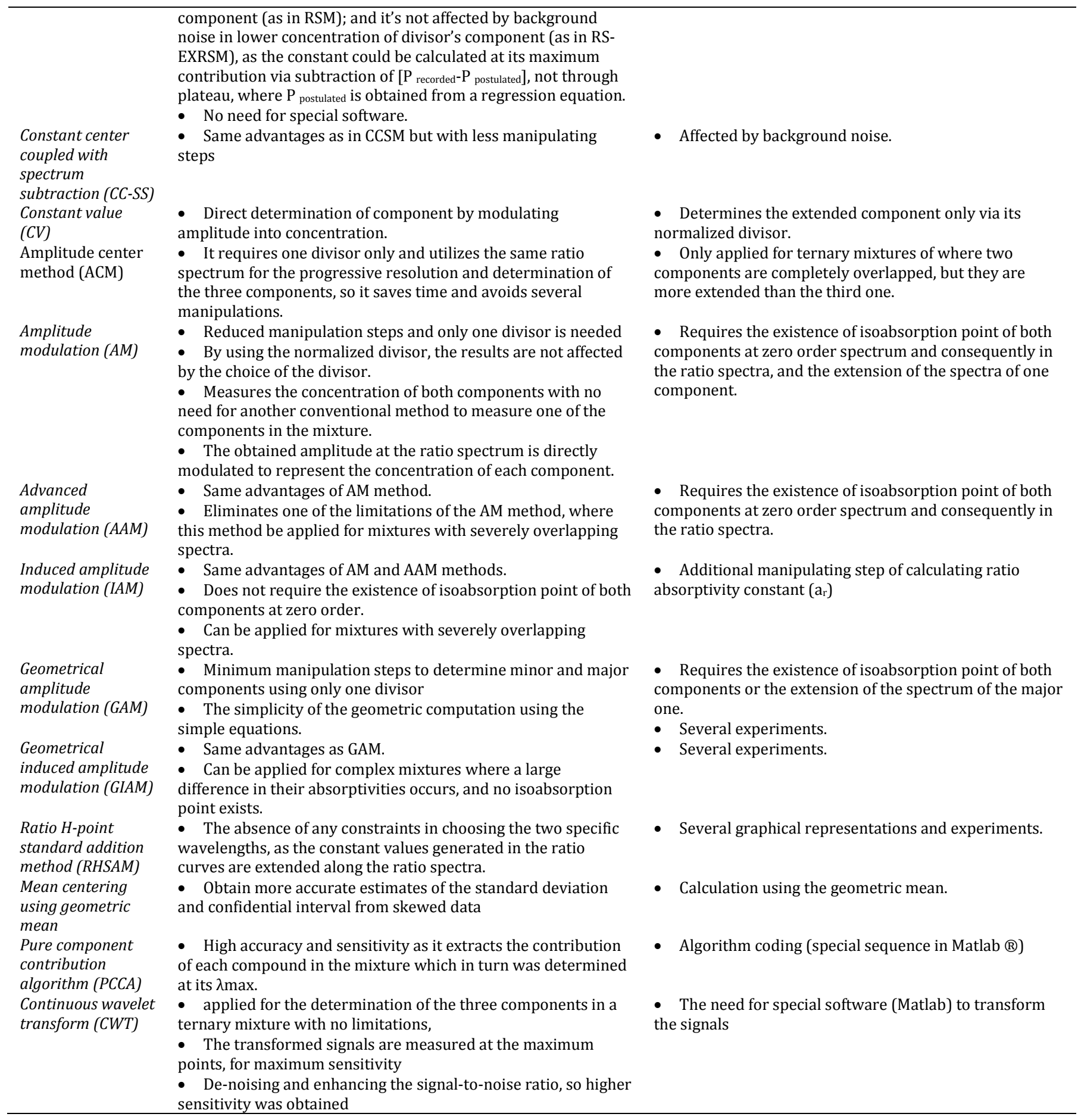

\section{CONFLICTS OF INTERESTS}

Declared none

\section{REFERENCES}

1. Harvey D. Modern analytical chemistry. United States of America: McGraw-Hill; 2000.

2. Hollas JM. Modern Spectroscopy. 4th Editon. UK: Wiley; 2004. p. 452.

3. Andrews DL. Molecular photophysics and spectroscopy. UK: Morgan and Claypool; 2014. p. 94.

4. Kenkel J. Analytical chemistry for technicians. Third ed. Greencastle, Ireland.: CRC Press; 2003. p. 584.
5. Raghubabu K, Mohan N, Kalyanaramu B, Ramdas C, Rao MN. Development of new visible spectrophotometric determination of tiaprofenic acid in bulk and formulations. Asian J Pharm Clin Res 2013;6:77-9.

6. Sreeja U, Gurupadayya B, Chandan R. Novel spectrophotometric methods for the quantification of desvenlafaxine In pure and pharmaceutical dosage form. Asian J Pharm Clin Res 2015;8:267-70.

7. Naga Raju K, Sunitha T, Sudheer Babu I. Quantitative estimation of riluzole using solubilizing agent by UVspectrophotometry. Int J Appl Pharm 2014;6:4-5.

8. Lotfy HM, Saleh SS, Hassan NY, Salem H. Novel two wavelength spectrophotometric methods for simultaneous determination 
of binary mixtures with severely overlapping spectra. Spectrochim Acta, Part A 2015;136:1786-96.

9. Bindaiya S, Bankey S, Jain D. Simultaneous determination of nitazoxanide and ofloxacin in tablet by ultraviolet spectrophotometry (dual wavelength method). Int J ChemTech Res 2010;2:11-5.

10. Ramadan NK, Mohamed HM, Moustafa AA. Simultaneous determination of rabeprazole sodium and domperidone. J Appl Pharm Sci 2011;1:73-80.

11. Prajapati J, Patel M, Prajapati R, Prajapati N. Simultaneous determination of Perindopril erbumine and Amlodipine besylate by absorption factor method. Int J Appl Biol Pharm Technol 2011;2:230-3.

12. Patel CV, Khandhar AP, Captain AD, Patel KT. Validated absorption factor spectrophotometric and reversed-phase high-performance liquid chromatographic methods for the determination of ramipril and olmesartan medoxomil in pharmaceutical formulations. Eurasian J Anal Chem 2007;2:160-71.

13. Lotfy HM, Hegazy MA, Rezk MR, Omran YR. Novel spectrophotometric methods for simultaneous determination of timolol and dorzolamide in their binary mixture. Spectrochim Acta Part A 2014;126:197-207.

14. Lotfy HM, Saleh SS, Hassan NY, Salem H. A comparative study of novel spectrophotometric methods based on isosbestic points; application on a pharmaceutical ternary mixture. Spectrochim Acta Part A 2014;126:112-21.

15. El-Ghobashy MR, Abo-Talib NF. Spectrophotometric methods for the simultaneous determination of a binary mixture of metronidazole and diloxanide furoate without prior separation. J Adv Res 2010;1:323-9.

16. Lotfy HM, Hassan NY, Elgizawy SM, Saleh SS. Comparative study of new spectrophotometric methods; an application on a pharmaceutical binary mixture of ciprofloxacin hydrochloride and hydrocortisone. J Chil Chem Soc 2013;58:1651-7.

17. Lotfy HM, Hegazy MA, Rezk MR, Omran YR. Comparative study of novel versus conventional two-wavelength spectrophotometric methods for analysis of spectrally overlapping binary mixture. Spectrochim Acta Part A 2015;148:328-37.

18. Samir A, Salem H, Abdelkawy M. New developed a spectrophotometric method for simultaneous determination of salmeterol xinafoate and fluticasone propionate in bulk powder and seritide diskus inhalation. Bull Fac Pharm Cairo Univ 2012;50:121-6.

19. Salem H, Lotfy HM, Hassan NY, El-Zeiny MB, Saleh SS. A comparative study of different aspects of manipulating ratio spectra applied for ternary mixtures: derivative spectrophotometry versus wavelet transform. Spectrochim Acta Part A 2015;135:1002-10.

20. Ghorpade SA, Sali MS, Kategaonkar AH, Patel DM, Choudhari VP, Kuchekar BS. Simultaneous determination of emtricitabine and tenofovir by the area under the curve and dual wavelength spectrophotometric method. J Chil Chem Soc 2010;55:115-7.

21. Abdelrahman MM. Simultaneous determination of cinnarizine and domperidone by the area under the curve and dual wavelength spectrophotometric methods. Spectrochim Acta Part A 2013;113:291-6.

22. Lotfy HM, Saleh SS, Hassan NY, Salem H. Computation of the geometric representation of novel spectrophotometric methods used for the analysis of minor components in pharmaceutical preparations. Spectrochim Acta Part A 2015;151:628-43.

23. Erk N. Analysis of binary mixtures of losartan potassium and hydrochlorothiazide by using high-performance liquid chromatography, ratio derivative spectrophotometric and compensation technique. J Pharm Biomed Anal 2001;24:603-61.

24. Lotfy HM, Saleh SS, Hassan NY, Elgizawy SM. Spectrophotometric and chromatographic methods for the determination of a binary mixture of sodium cromoglicate and xylometazoline hydrochloride. Anal Chem Indian J 2013;13:152-60.

25. Samir A, Lotfy HM, Salem H, Abdelkawy M. Development and validation of simultaneous spectrophotometric and TLC- spectro- densitometric methods for determination of beclomethasone dipropionate and salbutamol in combined dosage form. Spectrochim Acta Part A 2014;128:127-36.

26. Mohamed ME. First-derivative spectrophotometric determination of a mixture of pirbuterol hydrochloride and butorphanol tartrate. Anal Lett 1986;11:1323-39.

27. Hassan SM, Amer SM, Amer MM. Determination of fusidic acid and sodium fusidate in pharmaceutical dosage forms by firstderivative ultraviolet spectrophotometry. Analyst 1987;112:1459-61.

28. Ouanes S, Kallel M, Trabelsi H, Safta F, Bouzouita K. Zerocrossing derivative spectrophotometry for the determination of haloperidol in the presence of parabens. J Pharm Biomed Anal 1998;17:361-4.

29. El-Gindy A, Ashour A, Abdel-Fattah L, Shabana MM. First derivative spectrophotometric, TLC-densitometric, and HPLC determination of acebutolol HCL in the presence of its acidinduced degradation product. J Pharm Biomed Anal 2001;24:527-34.

30. Lotfy HM, Tawakkol SM, Fahmy NM, Shehata MA. Validated stability indicating spectrophotometric methods for the determination of lidocaine hydrochloride, calcium dobesilate, and dexamethasone acetate in their dosage forms. Anal Chem Lett 2013;3:208-25.

31. Yehia AM, Abd El-Rahman MK. Application of normalized spectra in resolving a challenging orphenadrine and Paracetamol binary mixture. Spectrochim Acta Part A 2015;138:21-30.

32. Wahbi AAM, Abdel-Razak O, Gazy AA, Mahgoub H, Moneeb MS. Spectrophotometric determination of omeprazole, lansoprazole and pantoprazole in pharmaceutical formulations. J Pharm Biomed Anal 2002;30:1133-42.

33. Lotfy HM, Tawakkol SM, Fahmy NM, Shehata A. A comparative study of novel spectrophotometric resolution techniques applied for pharmaceutical mixtures with partially or severely overlapped spectra. Spectrochim Acta Part A 2015;136:937-52.

34. Lotfy HM, Tawakkol SM, Fahmy NM, Shehata MA. Successive spectrophotometric resolution as a novel technique for the analysis of ternary mixtures of pharmaceuticals. Spectrochim Acta Part A 2014;121:313-23.

35. Lotfy HM, Fayez YM, Michael AM, Nessim CK. Simultaneous determination of mebeverine hydrochloride and chlordiazepoxide in their binary mixture using novel univariate spectrophotometric methods via different manipulation pathways. Spectrochim Acta Part A 2016;155:11-20.

36. El-Bardicy MG, Lotfy HM, El-Sayed MA, El-Tarras MF. Smart stability-indicating spectrophotometric methods for determination of binary mixtures without prior separation. J AOAC Int 2008;91:299-310.

37. Lotfy HM, Hagazy MA. Comparative study of novel spectrophotometric methods manipulating ratio spectra; an application on a pharmaceutical ternary mixture of omeprazole, tinidazole, and clarithromycin. Spectrochim Acta Part A 2012;96:259-70.

38. Lotfy HM, Hegazy M. Simultaneous determination of some cholesterol-lowering drugs in their binary mixture by novel spectrophotometric methods. Spectrochim Acta Part A 2013;113:107-14.

39. Lotfy HM. Determination of simvastatin and ezatimibe in combined tablet dosage forms by constant center spectrophotometric method Int J Pharm Pharm Sci 2012;4:673-9.

40. Saleh SS, Lotfy HM, Hassan NY, Salem H. A comparative study of progressive versus successive spectrophotometric resolution techniques applied for pharmaceutical ternary mixtures. Spectrochim Acta Part A 2014;132:239-48.

41. Lotfy HM, Saleh SS, Hassan NY, Elgizawy SM. Univariate versus multivariate spectrophotometric methods for simultaneous determination of complex binary mixtures with overlapped spectra: a comparative study. Anal Chem Lett 2013;3:70-84.

42. Saleh SS, Lotfy HM, Hassan NY, Elgizawy SM. A comparative study of validated spectrophotometric and TLC-spectrodensitometric methods for the determination of sodium cromoglicate and fluorometholone in ophthalmic solution. Saudi Pharm J 2013;21:411-21. 
43. Campins-Falco P, Verdu-Andres J, Bosch-Reig F. H-point standard additions method for resolution of binary mixtures with simultaneous addition of both analytes. Anal Chim Acta 1995;315:267-78

44. Hund E, Massart DL, Smeyers-Verbeke J. Evaluation of the Hpoint standard additions method (HPSAM) and the generalized $\mathrm{H}$-point standard additions method (GHPSAM) for the UVanalysis of two-component mixtures. J Pharm Biomed Anal 1999;21:23-42.

45. Abdollahi H. Simultaneous spectrophotometric determination of chromium (VI) and iron(III) with mixed chromogenic reagents by $\mathrm{H}$-point standard addition method and partial least squares regression. Anal Chim Acta 2001;442:327-36.

46. Yehia AM. Development and validation of new spectrophotometric ratio $\mathrm{H}$-point standard addition method and application to gastrointestinal acting drugs mixtures. Spectrochim Acta Part A 2013;109:193-200.

47. Afkhami A, Bahram M. Mean centering of ratio spectra as a new spectrophotometric method for the analysis of binary and ternary mixtures. Talanta 2005;66:712-20.

48. Afkhami A, Bahram M. A novel spectrophotometric method for the simultaneous kinetic analysis of ternary mixtures by mean centering of kinetic ratio profiles. Talanta 2006;68:1148-55.

49. Bahram M, Madrakian T, Bozorgzadeh E, Afkhami A. Micellemediated extraction for the simultaneous spectrophotometric determination of aluminum and beryllium using mean centering of ratio spectra. Talanta 2007;72:408-14.

50. Issa MM, Nejem RM, Stefan Van Staden RI, Aboul-Enein HY. New approach application of data transformation in mean centering of ratio spectra method. Spectrochim Acta Part A 2015;142:204-9.

51. Hegazy MA. A novel pure component contribution algorithm (PCCA) for extracting components' contribution from severely overlapped signals; application to UV-spectrophotometric data. Spectrochim Acta Part A 2015;151:405-14.

52. Afkhami A, Abbasi-Tarighat M. Application of a continuous wavelet transformation to the simultaneous kinetic determination of binary mixtures. Talanta 2009;78:424-31.

53. Afkhami A, Nematollahi D, Madrakian T, Abbasi-Tarighat M, Hajihadi M. Simultaneous spectrophotometric determination of binary mixtures of surfactants using continuous wavelet transformation. J Hazard Mater 2009;166:770-5.

54. Dinc E, Kaya S, Doganay T, Baleanu D. Continuous wavelet and derivative transforms for the simultaneous quantitative analysis and dissolution test of levodopa-benserazide tablets. J Pharm Biomed Anal 2007; 44:991-5.

55. Patel NS, Nandurbarkar VP, Patel AJ, Patel SG. Simultaneous spectrophotometric determination of celecoxib and diacerein in bulk and capsule by absorption correction method and chemometric methods. Spectrochim Acta Part A 2014;125:46-52.

56. Lotfy HM, Hegazy MA, Mowaka S, Mohamed EH. Novel spectrophotometric methods for simultaneous determination of amlodipine, valsartan and hydrochlorothiazide in their ternary mixture. Spectrochim Acta Part A 2015;140:495-508.

57. Salem H, Mohamed D. A comparative study of smart spectrophotometric methods for simultaneous determination of a skeletal muscle relaxant and an analgesic in combined dosage form. Spectrochim Acta Part A 2015;140:166-73.

58. Lotfy HM, Amer SM, Zaazaa HE, Mostafa NS. A comparative study of the novel spectrophotometric methods versus conventional ones for the simultaneous determination of Esomeprazole magnesium trihydrate and Naproxen in their binary mixture. Spectrochim Acta Part A 2015;151:538-46.

59. Kelani KM, Shalaby AA, Elmaamly MY, Halim MK. Spectrophotometric and chemometric methods for simultaneous determination of two anti-hypertensive drugs in their combined dosage form. Pharm Anal Acta 2015;6:1-11.

60. Attia KAM, Nassar MWI, El-Zeiny MB, Serag A. Different spectrophotometric methods applied for the analysis of a binary mixture of flucloxacillin and amoxicillin: a comparative study. Spectrochim Acta Part A 2016;161:64-9.

61. Hegazy MA, Abbas SS, Zaazaa HE, Essam HM. Conventional univariate versus multivariate spectrophotometric assisted techniques for simultaneous determination of perindopril arginine and amlodipine besylate in the presence of their degradation products. Spectrochim Acta Part A 2015;150:940-8.

62. Lotfy HM, Salem H, Abdelkawy M, Samir A. Spectrophotometric methods for simultaneous determination of betamethasone valerate and fusidic acid in their binary mixture. Spectrochim Acta Part A 2015;140:294-304.

63. Lotfy HM, Hegazy MA, Mowaka S, Mohamed EH. Validated spectrophotometric methods for simultaneous determination of omeprazole, tinidazole and doxycycline in their ternary mixture. Spectrochim Acta Part A 2016;153:321-32.

64. Lotfy HM, Mohamed D, Mowaka S. A comparative study of smart spectrophotometric methods for simultaneous determination of sitagliptin phosphate and metformin hydrochloride in their binary mixture. Spectrochim Acta Part A 2015;149:441-51.

65. Darwish HW, Bakheit AH, Naguib IA. Comparative study of novel ratio spectra and isoabsorption point based spectrophotometric methods: application on a binary mixture of ascorbic acid and rutin. J Anal Methods Chem 2016;2:1-12.

66. Lamie NT, Yehia AM. Development of normalized spectra is manipulating spectrophotometric methods for simultaneous determination of dimenhydrinate and cinnarizine binary mixture. Spectrochim Acta Part A 2015;150:142-50.

67. Hegazy MA, Lotfy HM, Rezk MR, Omran YR. Novel spectrophotometric determination of chloramphenicol and dexamethasone in the presence of non-labeled interfering substances using univariate methods and multivariate regression model updating. Spectrochim Acta Part A 2015;140:600-13.

68. El-Sayed MA. Innovative spectrophotometric methods for determination of almitrine dis mesylate and raubasine in duxil tablets. Anal Lett 2009;42:1882-99.

69. Abd El Kawy M, El Gindy AE, Hegazy M, Shokry ES. A novel spectrophotometric method for simultaneous determination of two binary mixtures containing hydrochlorothiazide by ratio subtraction. J Appl Sci Res 2010;6:918-26.

70. Farouk M, EL-Aziz 0, Hemdan A, Shehata MA. Simple novel spectrophotometric and spectrofluorimetric methods for determination of some anti-hypertensive drugs. J Am Sci 2011;7:300-12.

71. Lotfy HM, Monir HH, Abd El-aleem AE. Novel spectrophotometric methods for the determination of fluconazole in the presence of its oxidative degradation product. J Chil Chem Soc 2012;57:1199-207.

72. Hassan NY, Elgizawy SM, Lotfy HM, Saleh SS. Comparative study of spectrophotometric methods versus chemometric methods; an application on a pharmaceutical binary mixture of ofloxacin and dexamethasone. Int Res J Pure Appl Chem 2013;3:90-110.

73. Abdel-fattah L, Weshahy SA, Hassan NY, Mostafa NM, Boltia SA. Development and validation of spectrophotometric, chemometric and high pressure liquid chromatographic methods for the determination of cefepime hydrochloride in the presence of its acid and alkaline degradation products. Int J Anal Bioanal Chem 2013;3:86-96.

74. Baghdady YZ, Al-Ghobashy MA, Abdel-Aleem AE, Weshahy SA Two new spectrophotometric approaches to the simultaneous determination of ezetimibe and atorvastatin calcium. Int $\mathrm{J}$ Chem-Stud 2013;1:231-45.

75. Hegazy AM, Hassan NY, Metwally FH, Abdel-Kawy M. Application and validation of two smart spectrophotometric and an HP-TLC densitometric methods for determination of metoclopramide hydrochloride/paracetamol in raw material and in pharmaceuticals. Int J Pharm 2013;3:470-81.

76. Darwish HW. Application of smart spectrophotometric methods and artificial neural network for the simultaneous quantitation of olmesartan medoxamil, amlodipine besylate and hydrochlorothiazide in their combined pharmaceutical dosage form. Chem Cent J 2013;7:22-31.

77. Ezzeldin MI, Shokry E, Fouad MA, Elbagary RI. Application of chromatographic and spectrophotometric methods for the analysis of selected antihypertensive combination. Int J Anal Pharm Biomed Sci 2013;2:6-15.

78. Abdelaleem EA, Naguib IA, Zaazaa HE, Draz ME. Spectrophotometric methods for quantitative determination of 
a binary mixture of hydrochlorothiazide and amiloride hydrochloride without prior separation. Asian J Biomed Pharm Sci 2014;4:27-40.

79. Zaazaa HE, Abbas SS, Zeinab A, El-Zeany BA, EL-Haddad DA. Stability is indicating spectrophotometric methods for determination of tiemonium methyl sulphate in the presence of its degradation products. J Appl Pharm Sci 2014;4:33-49.

80. Lotfy HM, Amer SM, Zaazaa HE, Mostafa NS Spectrophotometric methods for quantitative determination of a binary mixture of naproxen sodium and domperidone maleate. Austin J Anal Pharm Chem 2015;2:1044-52.

81. Fouad MM. Novel spectrophotometric methods for simultaneous determination of ciprofloxacin hydrochloride and dexamethasone sodium phosphate in their binary mixture. Indo Am J Pharm Res 2015;5:2470-80.

82. Darwish HA, Metwally FH, El-Bayoumi A. Novel ratio subtraction and isoabsorption point methods for determination of ambroxol hydrochloride and doxycycline in their combined dosage form: development and validation. Trop J Pharm Res 2015;14:133-40.

83. Abdel-Ghany MF, Abdel-Aziz O, Mohammed YY. Validation of four different spectrophotometric methods for simultaneous determination of domperidone and ranitidine in bulk and pharmaceutical formulation. Spectrochim Acta Part A 2015;149:30-40.

84. Mostafa NM, Abdel-Fattah L, Weshahy SA, Hassan NY, Boltia SA. Validated stability indicating spectrophotometric methods for the determination of cefixime trihydrate in the presence of its acid and alkali degradation products. J AOAC Int 2015;98:35-45.

85. Elghobashy MR, Bebawy LI, Shokry RF, Abbas SS. Successive ratio subtraction coupled with constant multiplication spectrophotometric method for determination of hydroquinone in a complex mixture with its degradation products, tretinoin, and methylparaben. Spectrochim Acta Part A 2016;157:116-23.

86. Mohsen AM, Lotfy HM, Badawey AM, Salem H, Elkhateeb SZ Application of three novel spectrophotometric methods manipulating ratio spectra for resolving a pharmaceutical mixture of chlorphenoxamine hydrochloride and caffeine. Int J Pharm Pharm Sci 2013;5:478-87.

87. Essam HM, Abd-El-Rahman MK. Smart manipulation of ratio spectra for resolving a pharmaceutical mixture of methocarbamol and paracetamol. Spectrochim Acta Part A 2015;141:1-9.

88. Tawakkol SM, Farouk M, Elaziz OA, Hemdan A, Shehata MA. A comparative study between univariate spectrophotometry and multivariate calibration as analytical tools for simultaneous quantitation of moexipril and hydrochlorothiazide. Spectrochim Acta Part A 2014;133:300-6.

89. Ali NW, Abdelwahab NS, EL fatatry HM, Osman WM. Spectrophotometric methods for simultaneous determination of two hypouricemic drugs in their combined dosage form Pharm Anal Acta 2013;4:255-61.

90. Elzanfaly ES, Saad AS, Abd-Elaleem AB. Simultaneous determination of retinoic acid and hydroquinone in skin ointment using the spectrophotometric technique (difference ratio method). Saudi Pharm J 2012;20:249-53.

91. Elzanfaly ES, Saad AS, Abd Elaleem AE. A smart, simple spectrophotometric method for simultaneous determination of binary mixtures. J Pharm Anal 2012;2:382-5.

92. Lotfy HM, Saleh SS, Hassan NY, Elgizawy SM. A comparative study of the novel ratio difference method versus conventional spectrophotometric techniques for the analysis of binary mixture with overlapped spectra. Am J Anal Chem 2012;3:761-9.

93. Moustafa H, Fayez Y. Spectrophotometric methods manipulating ratio spectra for simultaneous determination of binary mixtures with sever overlapping spectra: a comparative study. Spectrochim Acta Part A 2014;133:759-66.

94. Mohamed HM. A study of selective spectrophotometric methods for simultaneous determination of Itopride hydrochloride and rabeprazole sodium binary mixture: resolving to sever overlapping spectra. Spectrochim Acta Part A 2015;136:1308-15.
95. Moustafa AA, Salem H, Hegazy M, Ali O. Evaluating the efficiency of spectral resolution of univariate methods manipulating ratio spectra and comparing to multivariate methods: an application to the ternary mixture in common cold preparation. Spectrochim Acta Part A 2015;137:1363-73.

96. Attia KAM, Nassar MWI, El-Zeiny M, Serag A. Different approaches in manipulating ratio spectra applied for the analysis of cefprozil in the presence of its alkaline-induced degradation product: a comparative study. Spectrochim Acta Part A 2015;145:289-94.

97. Lamie NT. Comparative study of spectrophotometric methods manipulating ratio spectra: an application on a pharmaceutical binary mixture of cinnarizine and dimenhydrinate. Spectrochim Acta Part A 2015;141:193-201.

98. Abdel-Aleem EA, Hegazy MA, Sayed NW, Abdelkawy M, Abdelfatah RM. Novel spectrophotometric determination of flumethasone pivalate and clioquinol in their binary mixture and pharmaceutical formulation. Spectrochim Acta Part A 2015;136:707-13.

99. Fayez YM. Simultaneous determination of some antihypertensive drugs in their binary mixture by novel spectrophotometric methods. Spectrochim Acta Part A 2014;132:446-51.

100. Moustafa AA, Salem H, Hegazy M, Ali O. Stability indicating spectrophotometric and chemometric methods for determination of buflomedil in the presence of its acid-induced degradation products. Anal Chem Lett 2013;3:342-58.

101. Zaazaa HE, Elzanfaly ES, Soudi AT, Salem MY. Application of the ratio difference spectrophotometry to the determination of ibuprofen and famotidine in their combined dosage form; comparison with previously published spectrophotometric methods. Spectrochim Acta Part A 2015;143:251-5.

102. Abdel-Moety EM, Badawey AM, Essam HM, Alamine FMA. Stability-indicating methods for the determination of gatifloxacin in the presence of its acid degradation product (s). Int J Drug Dev Res 2015;7:1-8.

103. Lotfy HM, Hegazy MA, El-aziz MM, Fattah LEA. Stability is indicating spectrophotometric methods determination of nicardipine in the presence of its alkaline induced degradation products. Int J Pharm Pharm Sci 2016;8:62-6.

104. Yehia AM, Arafa RM, Abbas SS, Amer SM. Ratio manipulating spectrophotometry versus chemometry as stability indicating methods for cefquinome sulfate determination. Spectrochim Acta Part A 2016;153:231-40.

105. Riad SM, Abd El-Rahman MK, Fawaz EM, Shehata MA. A comparative study between three stability indicating spectrophotometric methods for the determination of diatrizoate sodium in the presence of its cytotoxic degradation product based on the two-wavelength selection. Spectrochim Acta Part A 2015;145:254-9.

106. Lamie NT. Selective determination of itraconazole in the presence of its oxidative degradation product by a new spectrophotometric method. Spectrosc Spectral Anal 2015;35:502-6.

107. Riad SM, Salem H, Elbalkiny HT, Khattab FI. Validated univariate and multivariate spectrophotometric methods for the determination of pharmaceuticals mixture in complex wastewater. Spectrochim Acta Part A 2015;140:451-61.

108. Abdel-Halim LM, Abd-El-Rahman MK, Ramadan NK, El Sanabary HFA, Salem MY. A comparative study between recent methods manipulating ratio spectra and classical methods based on two-wavelength selection for the determination of a binary mixture of antazoline hydrochloride and tetryzoline hydrochloride. Spectrochim Acta Part A 2016;159:98-105.

109. Hegazy MA, Al-Ghobashy MA, Eltanany BM, Khattab FI. Spectral resolution and simultaneous determination of oxymetazoline hydrochloride and sodium cromoglycate by derivative and ratio-based spectrophotometric methods. Eur J Chem 2015;6:319-24.

110. Lamie NT. Simultaneous determination of binary mixture of amlodipine besylate and atenolol-based on dual wavelengths. Spectrochim Acta Part A 2015;149:201-7. 
111. Fayez YM, Elghobashy MR, Goda ZM, Shehata MA. Comparative study on four spectrophotometric methods manipulating ratio spectra for the simultaneous determination of a binary mixture of diflucortolone valerate and isoconazole nitrate. Bull Fac Pharm Cairo Univ 2016;54:39-47.

112. Lotfy HM. Absorbance subtraction and amplitude modulation as novel spectrophotometric methods for the analysis of binary mixtures. Int J Pharm Pharm Sci 2014;6:735-41.

113. Dang Hoang V, Thi Loan N, Thi Tho V, Thi Nguyen HM. UV spectrophotometric simultaneous determination of cefoperazone and sulbactam in pharmaceutical formulations by derivative, Fourier and wavelet transforms. Spectrochim Acta Part A 2014;121:704-14.

114. Elzanfaly ES, Hassan SA, Salem MY, El-Zeany BA. Continuous wavelet transform, a powerful alternative to derivative spectrophotometry in the analysis of binary and ternary mixtures: a comparative study. Spectrochim Acta Part A 2015;151:945-55

115. Ashour A, Hegazy MA, Abdel-Kawy M, ElZeiny MB. Simultaneous spectrophotometric determination of overlapping spectra of paracetamol and caffeine in laboratory prepared mixtures and pharmaceutical preparations using continuous wavelet and derivative transform. J Saudi Chem Soc 2015;19:186-92.

\section{How to cite this article}

- Hayam M Lotfy, Sarah S Saleh. Recent development in ultraviolet spectrophotometry through the last decade (20062016): a review. Int J Pharm Pharm Sci 2016;8(10):40-56. 